\title{
DETALHAMENTO DAS FASES PARA O DESENVOLVIMENTO DE UM LAYOUT DO TIPO JOB-SHOP PARA FINS DE ESTUDO EM MODELAGEM E SIMULAÇÃO
}

\section{DETAILING STEPS FOR THE DEVELOPMENT OF A JOB-SHOP LAYOUT TO BE USED IN MODELING AND SIMULATION RESEARCH}

\author{
Shih Yung Chin ${ }^{1}$; Eduardo Vila Gonçalves Filho ${ }^{2}$ \\ ${ }^{1}$ Universidade de São Paulo - USP - São Carlos - Brasil sychin@sc.usp.br \\ ${ }^{2}$ Universidade de São Paulo - USP - São Carlos - Brasil evila@ sc.usp.br
}

\begin{abstract}
Resumo
Quando um estudo de layout se inicia por causa de uma necessidade de melhoria de uma empresa real, tanto o formato do chão de fábrica quanto o número total de máquinas já são conhecidos. Caso contrário, deve-se iniciar a partir das informações de demanda. O objetivo deste trabalho é apresentar detalhadamente as fases durante o desenvolvimento de layout job-shop, considerando que o mesmo ainda não existe, discutindo as dificuldades encontradas, as diversas possibilidades de formação do chão de fábrica bem como as possibilidades de formação do vão vazio. Este artigo inicialmente apresenta revisão bibliográfica e depois, um conjunto de fluxogramas para a geração de dados em cada etapa de desenvolvimento de layout. Para avaliação de layout, alguns critérios de seleção de recursos são adotados e implementados em um modelo de simulação usando redes de Petri colorida, e ao executá-lo, resultados são comparados entre si. A conclusão sugere que os resultados da literatura devem ser rediscutidos.
\end{abstract}

Palavras-chave: concepção de layout job-shop, geração e manipulação de dados, desempenho do sistema, simulação.

\section{Introdução}

Num cenário de grande competitividade entre as empresas é inaceitável que um sistema produtivo opere de forma ineficiente porque isso implica em aumento de custos e consequientemente aumento nos preços finais ao consumidor ou redução da margem de lucro para as empresas. Pequenas mudanças no sistema produtivo podem trazer grande vantagem competitiva tais como redução de movimentação de peças, melhor aproveitamento de recursos, menor desperdício, dentre outras.

As empresas costumam implementar o layout funcional para trabalhar com alta variedade e baixa quantidade. Entretanto o grande problema deste layout é a grande locomoção de peças entre máquinas. A idéia dos arranjos físicos distribuídos, inicialmente propostos por Montreuil et al. 
(1991), é justamente minimizar os lead-times fazendo espalhar os diferentes tipos de máquinas do layout funcional no chão de fábrica tornando possível maior proximidade entre elas.

Geralmente os trabalhos referentes ao distribuído apresentam a formulação em QAP (Quadratic Assignment Problem), cujas máquinas são representadas em formato quadrado ou retangular e o distanciamento entre uma máquina à outra pode ser obtido tanto por distância euclidiana quanto por retangular. A contabilização da distância é feita da seguinte forma: Conhecendo todas as etapas de processamento das peças (os tipos de máquinas requisitados por cada peça) é possível obter o fluxo (contabilizando $\mathrm{n}(\mathrm{t})$ vezes a distância euclidiana), onde n(t) é o arredondamento de $\mathrm{TL}(\mathrm{t}) / \mathrm{C}$; TL(t) é o tamanho do lote num instante t; C é o tamanho do transportador utilizado para o transporte de peças entre máquinas.

Recentemente, os trabalhos de Benjaafar e Sheikhzadeh (2000), Lahmar e Benjaafar (2005) e Júnior e Filho (2007) têm se direcionado em estudos comparativos entre o tradicional (funcional), com os layouts distribuídos de tal forma a analisar em que situações um é mais vantajoso que o outro.

Todavia QAP é uma abordagem estática, ou seja, desconsidera uma série de variáveis dinâmicas. Por exemplo, numa situação real de funcionamento, comumente diversos recursos entram em conflito fazendo com que peças estejam mais tempo na fábrica do que deveria estar aumentando assim o lead-time. Para evitar esses conflitos, é necessário escolher adequadamente os recursos envolvidos na produção da peça de modo a minimizar tais conflitos, o que implica em lidar com programação da produção, ou seja, alocar atividades (peças) de forma criteriosa nos recursos produtivos. Uma forma de lidar com programação é pelo método tradicional, que é o uso de gráfico de Gantt. O problema desta ferramenta é a dificuldade em lidar com a programação de várias peças em vários tipos de recursos.

Mesmo assim, QAP também pode ser usado desde que inclua na análise essas variáveis dinâmicas. Benjaafar (1998) chega a apresentar uma série de formulações matemáticas para se estimar o tamanho de fila para uma fábrica em pleno funcionamento, além de outras variáveis, sendo assim, é possível avaliar o desempenho de todo sistema. Mas o próprio autor reconhece das dificuldades de trabalhar por este método em cada instante de tempo porque estas formulações necessitam de constantes reformulações e recálculos durante o funcionamento da empresa.

Outra forma para lidar tanto com a programação quanto às variáveis dinâmicas é por meio da modelagem e simulação. Uma vez realizada a modelagem, tanto o cálculo das variáveis quanto a parte de programação é automatizada.

Durante o desenvolvimento de um projeto de layout, de um modo geral, o projetista responsável se depara com duas situações: A de melhorar o que já existe (reprojetar) ou então desenvolver um totalmente novo. Na primeira, basta coletar as informações da empresa e com a 
proposta de alguma melhoria, realizar estudos comparativos com o existente antes de realizar alterações necessárias (como vem sendo abordado pelos artigos da literatura referentes ao layout distribuído). Já no segundo caso, é necessário realizar uma série de etapas antes de conceber um sistema produtivo, tais como obter e analisar as informações de mercado, as reais possibilidades de formatação de layout, os impactos que um vão vazio pode causar no desempenho do sistema (quando a máquina for muito cara de ser adquirida e este é uma situação que realmente pode acontecer). Muitos trabalhos ignoram estes pequenos detalhes durante o estudo do layout, mas que podem ser aspectos de diferenciação.

Este artigo, portanto, tem como objetivo introduzir passo a passo etapas para a concepção de um layout job-shop (considerando que a fábrica de fato ainda não existe) apresentando uma série de fluxogramas que auxilie o projetista, que nada mais é do que automatizar a geração dos dados usando códigos de programação a serem inseridos num modelo de simulação (usando qualquer simulador). Alguns critérios de seleção de recursos são discutidos, analisados e implementados ao modelo, e durante a simulação, coletou-se resultados para os possíveis formatos do chão de fábrica, as possibilidades de posição do vão vazio, etc.

Para cumprir aos objetivos propostos, a metodologia adotada é pesquisa de natureza bibliográfica, fazendo revisão da literatura referente ao layout distribuído. O método escolhido foi usar modelagem e simulação em Redes de Petri colorida para simular as diversas combinações dos critérios de seleção de recursos, por configuração, para cada layout e os dados coletados são de natureza quantitativa, cujo parâmetro medido foi tempo de consolidação do pedido.

\section{Geração dos tipos de peças}

Esta é a primeira etapa que precisa ser definida antes de se projetar qualquer tipo de layout. É importante também conhecer as máquinas por onde cada peça irá percorrer e que tipo de ferramental deva ser utilizado. Com isso, estimando as quantidades de cada peça que o mercado solicita, é possível realizar o dimensionamento do número total de máquinas (definindo assim o tamanho do layout). A Tabela 1 apresenta um exemplo de quatro peças, com as suas operações e seus respectivos ferramentais. Para a peça de código 2, por exemplo, existem 8 operações, sendo a primeira realizada na máquina 4 usando o ferramental 7 , e assim por diante. Uma característica importante das máquinas é que existe um mecanismo de acoplagem de blocos de ferramentas. Assim caso o ferramental solicitado pela peça não esteja no bloco, é necessário efetuar setup.

É importante lembrar que as operações consecutivas realizadas no mesmo tipo de máquina (tais como 61 e 62) são realizadas na mesma máquina, sem a necessidade de efetuar locomoções, apenas mudando a posição do bloco de ferramentas de 1 para o ferramental 2. Isso é desejável para minimizar o erro esporádico de fabricação decorrente da fixação da peça na máquina. 
Tabela 1 - Exemplo de representação das operações e ferramentais por tipo de peça

\begin{tabular}{|c|c|c|c|c|c|c|c|c|c|}
\hline $\begin{array}{l}\text { Cód. } \\
\text { Peça }\end{array}$ & $\begin{array}{c}\text { N. } \\
\text { Processos }\end{array}$ & \multicolumn{9}{|c|}{ Operações / ferramental } \\
\hline $\mathbf{1}$ & 2 & 58 & 21 & & & & & & \\
\hline $\mathbf{2}$ & 8 & 47 & 24 & 62 & 49 & 62 & 43 & 61 & 62 \\
\hline $\mathbf{3}$ & 1 & 81 & & & & & & & \\
\hline $\mathbf{4}$ & 6 & 73 & 17 & 38 & 36 & 18 & 92 & & \\
\hline
\end{tabular}

Fonte: Autoria própria (2008)

O fluxograma utilizado para gerar todas as características das peças está apresentado na Figura 1. Note que os pesos das peças bem como os tempos de processamento em cada máquina também podem ser gerados. No caso dos pesos, está ilustrado um exemplo que as peças variam conforme uma distribuição $(3 ; 5 ; 7) \mathrm{kg}$ e quanto ao processamento variando em cada máquina de 1 a 300 segundos. Com este fluxograma, e os demais seguintes, podem ser implementados em códigos de programação e por fim serem lidos pelos modelos de simulação.

Figura 1 - Fluxograma para a geração das características das peças

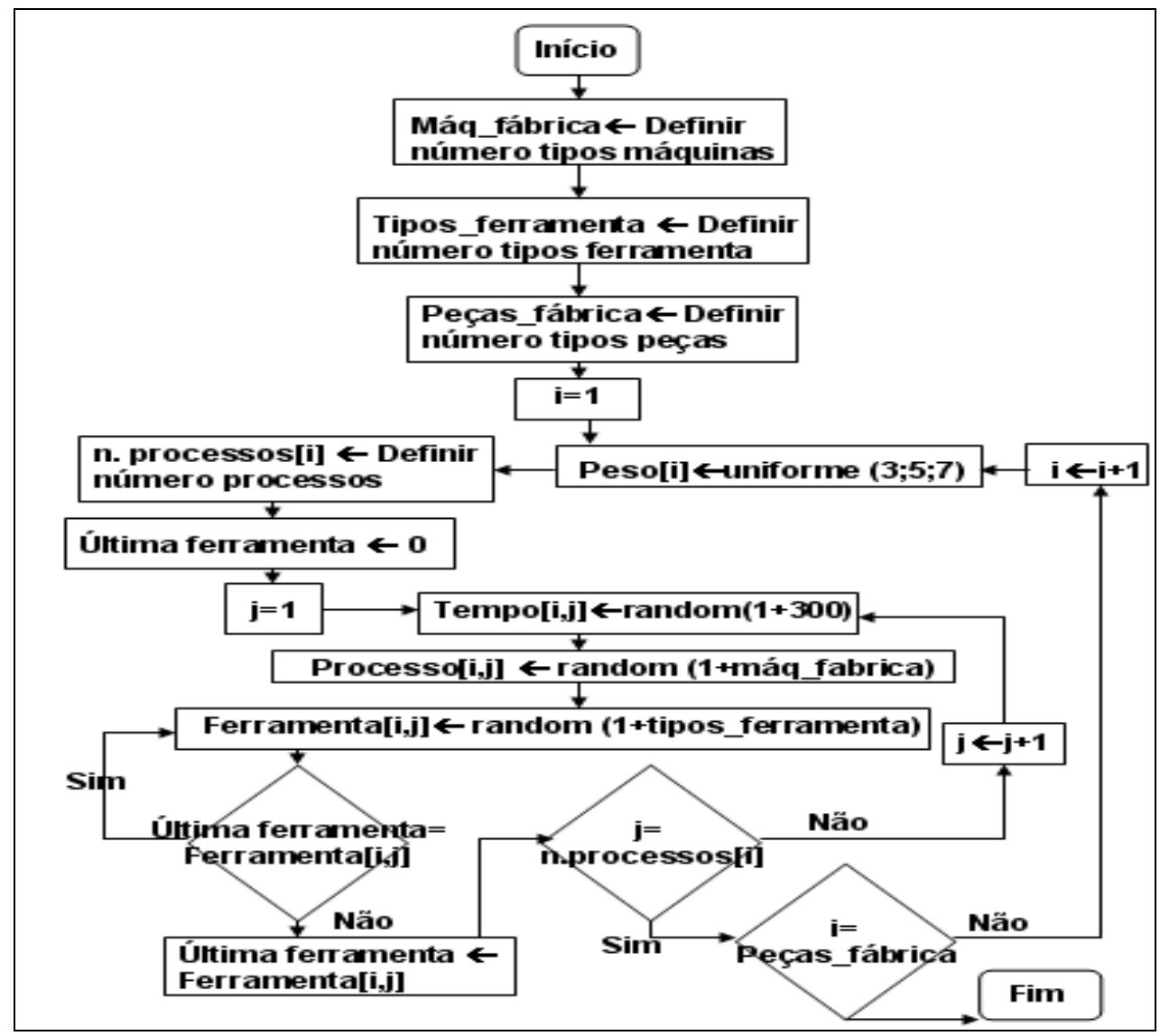

Fonte: Autoria própria (2008)

\section{Geração da demanda}

A etapa seguinte é gerar dados de demanda. Basicamente são necessárias informações sobre os tipos de peça e quantidade. Considerando, por exemplo, que o tópico 2 tenha gerado 100 peças 
(isto é, a empresa só é capaz de produzir 100 peças), a geração desta lista de demanda é na realidade escolha aleatória de vários tipos de peças de um conjunto de 100. O fluxograma apresentado na Figura 2 é genérico para infinitos tipos de peças e gera o perfil diário para todos os clientes, sendo um pedido por cliente. Assim, se existirem n clientes, o loop a ser realizado equivale a n vezes. Pode ser gerado também o lote de cada tipo de peça, no caso, está ilustrado um exemplo variandose de 1 a 3 unidades.

Figura 2 - Fluxograma para a geração do perfil de demanda para todos os clientes

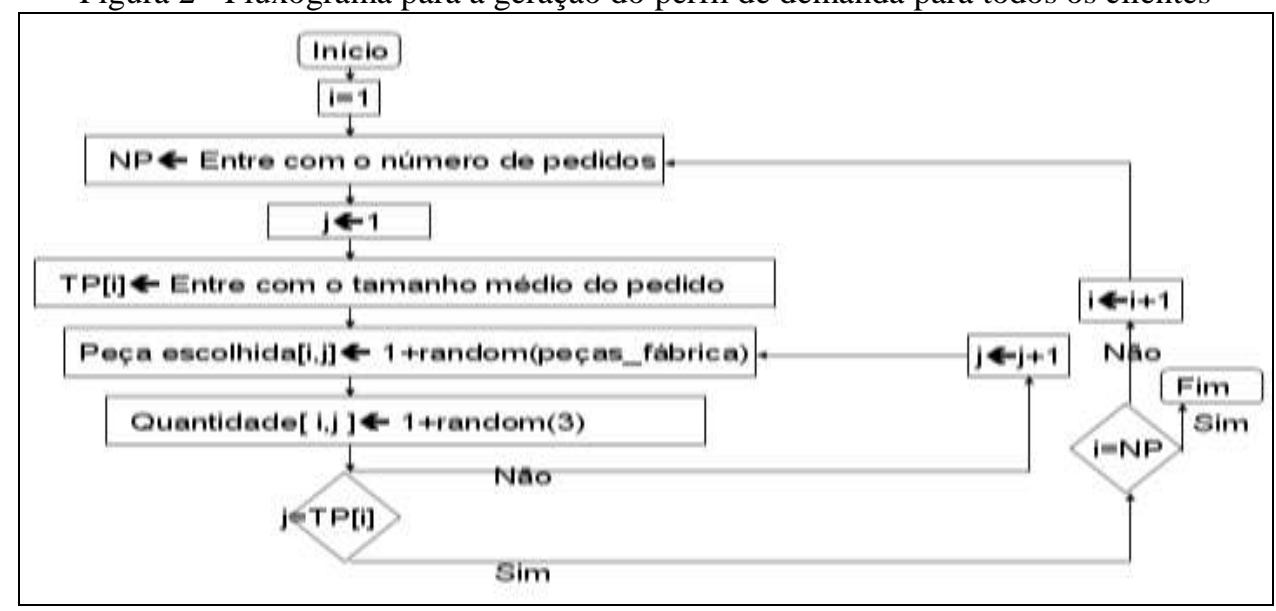

Fonte: Autoria própria (2008)

Somando-se os tempos que cada lote de peça requisita em cada tipo de máquina, é possível conhecer o número de máquinas de cada tipo necessário para concretizar a demanda, como mostrado no tópico 4.

\section{Dimensionamento de máquinas}

Este tópico apresenta uma breve descrição sobre o dimensionamento das máquinas. Como já é uma etapa já bastante conhecida na literatura, o importante neste trabalho não é detalhar como o dimensionamento é realizado em si, mas sim o impacto que este pode causar no desempenho do sistema produtivo. Basicamente, os passos necessários para a realização do dimensionamento são: Definir a demanda de cada peça (quantidade, que foi definido no tópico 3); Identificar as máquinas envolvidas em cada etapa de processamento da peça e seus respectivos tempos de operação (que foram definidos no tópico 2); definir turnos de trabalho. A expressão matemática (1) apresenta uma forma para o cálculo do número de réplicas para cada tipo de máquina, onde o numerador da expressão contabiliza os tempos que um determinado tipo de máquina é requisitado por todas as peças. O valor obtido é uma estimativa, isso porque esta expressão desconsidera os deslocamentos, os conflitos de uso das máquinas, etc. Desta forma, é possível criar códigos em qualquer linguagem de programação usando o fluxograma, como apresentado na Figura 3, onde contador é o tipo de 
peças de cada pedido. Como o fluxograma é para cada cliente, deve-se fazer n vezes, onde n é o número total de clientes.

$$
\text { n.maq } q_{(i)}=\frac{\sum_{j=1}^{J} \text { tempo processamento } \operatorname{maq}_{(i)}(h)}{\text { Turno detrabalho }(h)}
$$

i: tipo de máquina;

$\mathrm{j}$ : conta total peças de todos os pedidos;

$\mathrm{J}$ : Total de peças de todos os pedidos.

Figura 3 - Fluxograma para o cálculo do número de réplicas de cada máquina para cada pedido

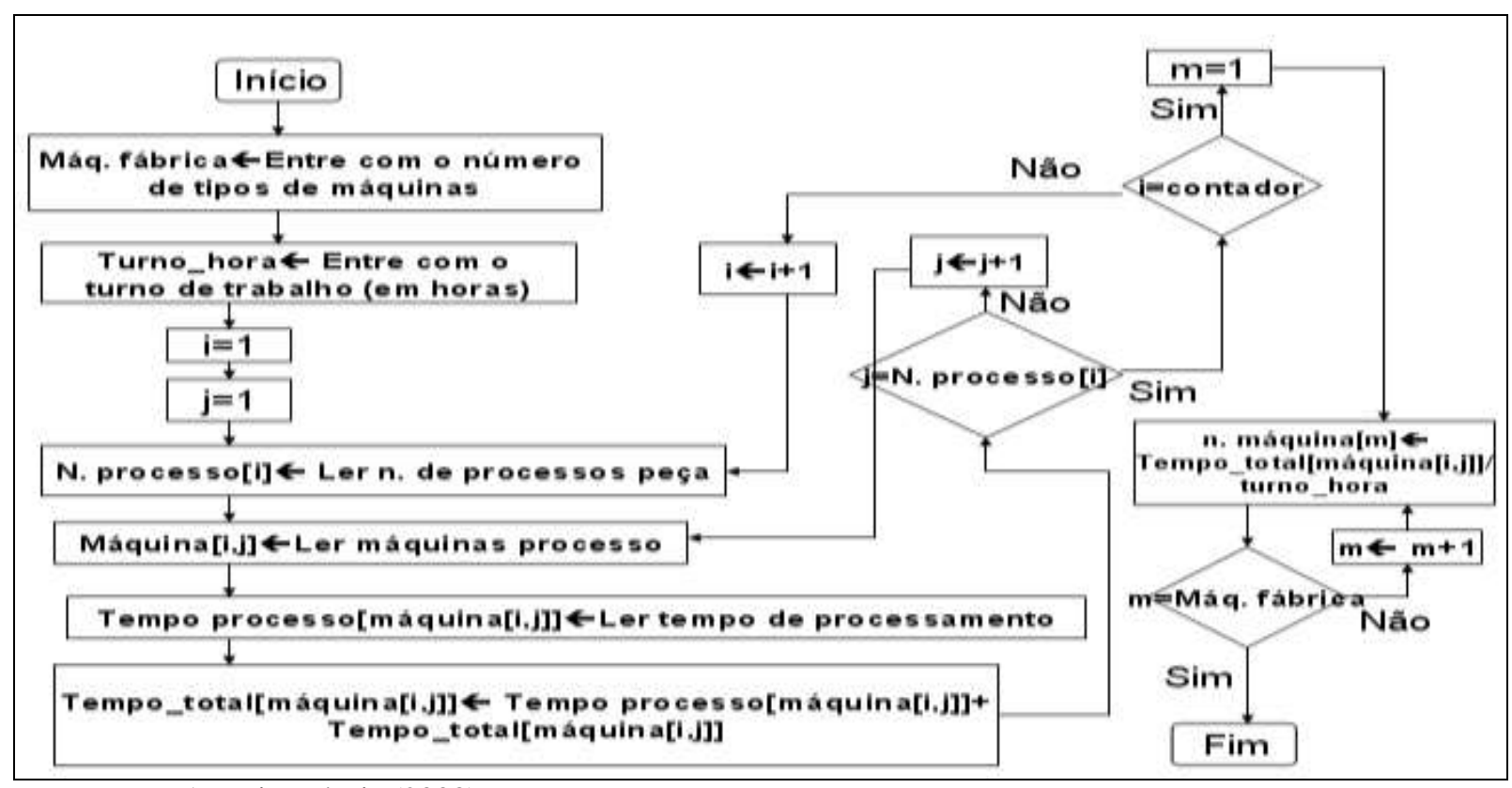

Fonte: Autoria própria (2008)

\section{Possíveis configurações da fábrica e geração de uma matriz de distância De-Para para cada configuração}

Ao conhecer o número de máquinas necessárias, o projetista também sabe que deve existir pelo menos o mesmo número de locais onde as máquinas serão alocadas. A principal questão neste momento é como será o formato do chão de fábrica. Este formato é obtido aplicando m.m.c. (mínimo múltiplo comum) sobre o número total de máquinas e o procedimento para a geração de todos os possíveis formatos pode ser representado por um fluxograma, como apresentada na Figura 4, onde x é o número de linhas e y é o número de colunas do chão de fábrica. A partir deste momento também podem ser geradas as matrizes de distâncias De-Para para cada formato de chão de fábrica, usando também um fluxograma, como mostrada na Figura 5. Cada matriz de distância obtida contém valores de distância entre os locais (onde as máquinas serão alocadas) para apenas um único formato. Assim, se houverem cinco formatos possíveis, significa que existem cinco matrizes de distância De-Para. 
Figura 4 - Fluxograma para a obtenção de todos os possíveis formatos de chão de fábrica

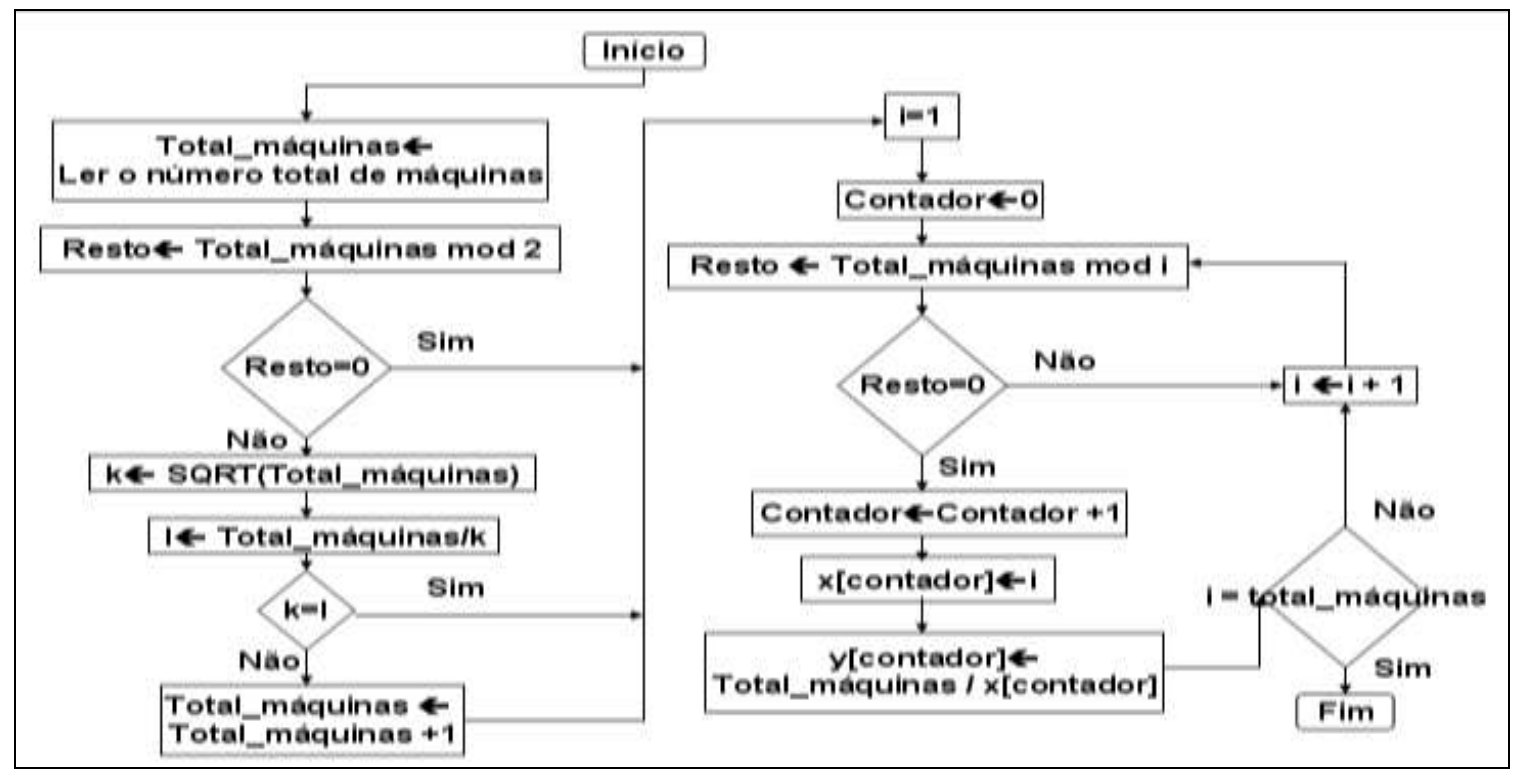

Fonte: Autoria própria (2008)

Figura 5 - Fluxograma para a obtenção das distâncias entre os locais (De-Para), variando conforme a o resultado do fluxograma da Figura 4

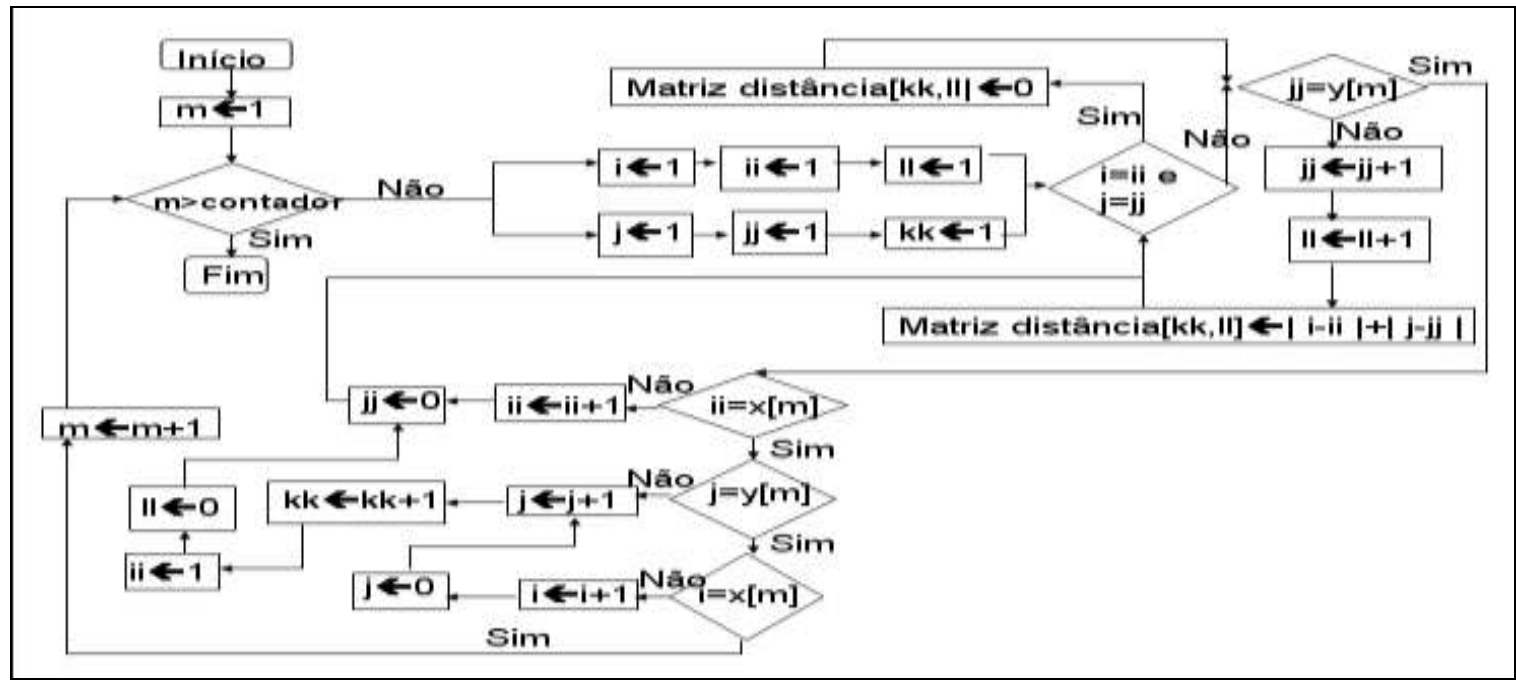

Fonte: Autoria própria (2008)

Considere que foi obtido, usando o fluxograma da Figura 3, um total de 42 máquinas. Assim, existem ao todo sete possibilidades, com a representação $(\mathrm{x}) \mathrm{x}(\mathrm{y})$, onde (x) é número de linhas e (y) é o número de colunas: 2x21, 6x7, 42x1, 1x42, 7x6, 21x2, 1x42. Portanto, a fábrica deve conter este mesmo número de espaços para a instalação das máquinas. Se houvessem 25 máquinas: $5 \times 5,25 \times 1,1 \times 25$.

\section{Geração dos layouts}

Tópicos anteriores não ensinam como gerar os diferentes tipos de layouts. Com o 
dimensionamento definido, o objetivo deste tópico é gerar apenas amostras de cada tipo de layout, sem se preocupar com a forma de alocação (ou seja, correta alocação das máquinas nos locais obtidos no tópico 4). Portanto, por enquanto as amostras geradas serão representadas na horizontal.

\subsection{Layout funcional}

A característica principal deste tipo de layout é a alocação dos mesmos tipos de máquinas uma próxima a outra. A Figura 6 apresenta um fluxograma capaz de gerar um layout funcional, onde $\mathrm{M}$ representa o total de tipos de máquinas, $\mathrm{Nm}$ representa as réplicas de cada tipo $\mathrm{m}$ e $\sum_{m=1}^{M} N_{m}$ representa o total de máquinas, ou melhor, total de máquinas que compõe o layout.

Figura 6 - Fluxograma para a geração do layout funcional

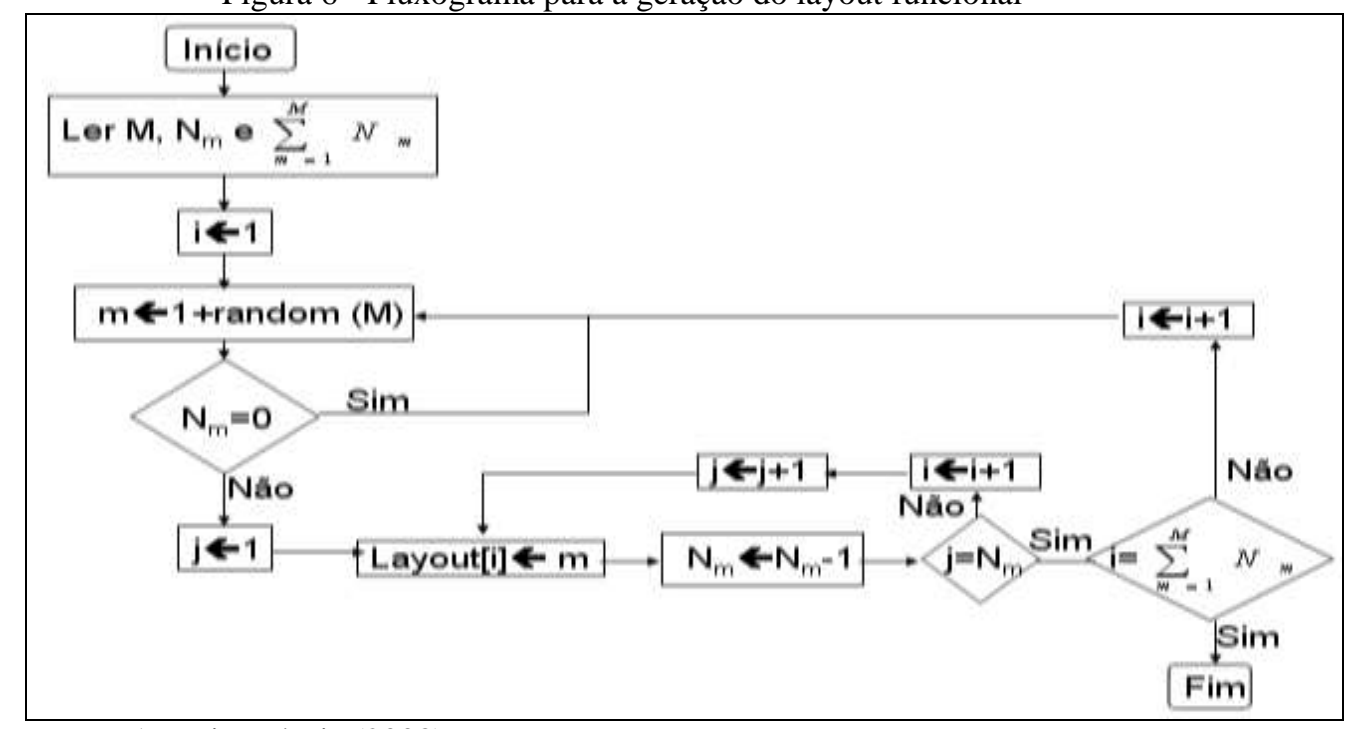

Fonte: Autoria própria (2008)

\subsection{Aleatoriamente distribuído}

Como o próprio nome já sugere, este é obtido aleatoriamente, ou seja, as máquinas são selecionadas sem uma ordem especial até que não reste mais nenhuma máquina. A Figura 7 apresenta uma metodologia para a obtenção deste tipo de arranjo. As máquinas escolhidas ocupam as posições de "1" até "total máquinas" e este procedimento só termina quando a variável "total máquinas" se iguala a $\sum_{m=1}^{M} N m$. As posições representam as diversas localidades do chão de fábrica onde as máquinas serão alocadas. 
Figura 7 - Fluxograma para a obtenção do arranjo aleatoriamente distribuído

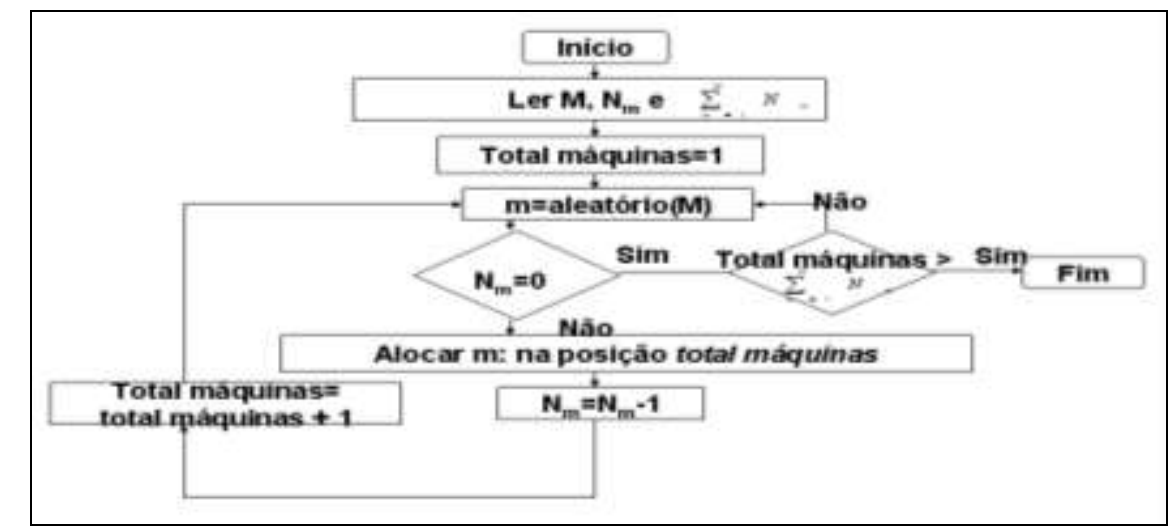

Fonte: Autoria própria (2008)

\subsection{Parcialmente distribuído}

Benjaafar e Sheikhzadeh (2000) apresentam dois graus de desagregação de máquinas do mesmo tipo. Quando é de primeiro grau, significa que são formados no chão de fábrica dois grupos (duas estações de trabalho) de mesmo tipo de máquina. A mesma análise serve para o de segundo grau (formação de três grupos em três localidades diferentes do mesmo tipo de máquina). Em comparação ao aleatoriamente distribuído, o parcialmente distribuído é mais complexo de representá-lo em fluxograma. Assim, os passos descritos abaixo irão auxiliar na obtenção de um layout parcialmente distribuído.

Passo 1: Leia os tipos de máquinas $(\mathrm{M})$ e réplicas de cada uma delas $\left(\mathrm{N}_{\mathrm{m}}\right)$;

Passo 2: Escolha aleatoriamente uma máquina. Entre também com o número de grupo desejado, por exemplo ( $\mathrm{k}=2$ ou $\mathrm{k}=3$ ). Divida $\mathrm{N}_{\mathrm{m}}$ por $\mathrm{k}$. Arredonde o resultado da divisão caso seja um número decimal. Fazendo isso, é possível conhecer quantas réplicas da mesma máquina em cada grupo.

Passo 3) Selecione os grupos de máquinas obtidos no passo 2 e aloque-os com se fosse na horizontal. É necessário fazer com que o código de programação garanta que dois grupos ou três grupos de mesmo tipo de máquina não sejam selecionados sucessivamente. Caso isso ocorra, será obtido um layout funcional e não um layout parcialmente distribuído.

\subsection{Maximamente distribuído}

A geração deste tipo de layout tem fundamentação no conceito de Minimax, proposto por Francis e White (1974), que é uma função objetivo de minimizar a maior distância entre máquinas distintas. Este cálculo pode ser representado por um fluxograma. Este serve para calcular o grau de distribuição de apenas um layout gerado aleatoriamente. O melhor layout aleatoriamente distribuído 
é também chamado de maximamente distribuído. Assim, se tiver uma amostra de tamanho n, devese usar o fluxograma apresentado $n$ vezes.

O fluxograma citado pode ser melhor entendido se separado em duas partes, sendo a parte 1 responsável pelo armazenamento das posições das réplicas de cada tipo de máquina (Figura 8). Já a segunda parte (Figura 9), continuação da parte 1, ensina como obter o valor do grau de distribuição, onde a variável "Distância[k]" recebe inicialmente um valor suficientemente grande. Este segundo identifica todas as menores distâncias de cada tipo de máquina obtidas na parte 1 . O valor da soma de todas estas menores distâncias de cada máquina dividido pelo número de tipos de máquinas define o grau de distribuição para o layout gerado. Realizando todas estas etapas para n (muito grande) de amostras de layout, o menor deles é chamado de maximamente distribuído.

Até agora tanto os locais, o número de tipos de máquinas e suas respectivas réplicas são conhecidos. Também os layouts (em formato horizontal) foram gerados. Antes de fazer a alocação em si, é preciso compreender alguns detalhes. Ainda com relação ao tópico 4, se houvessem 23 máquinas (número ímpar), são necessários 23 locais. Pela lógica, nenhuma empresa adotaria um conjunto enfileirado de 23 máquinas, mas sim utiliza de construção retangular. Sendo assim, devese somar um ao total de máquinas para que o formato retangular possa ser obtido. Portanto, com 24 locais, as possibilidades são $2 \times 12,4 \times 6,8 \times 3,24 \times 1,1 \times 24,3 \times 8,6 \times 4,12 \times 2$. Por causa da soma de uma unidade, surgem os chamados "dummy departments".

Figura 8 - Fluxograma para o cálculo do grau de distribuição para um layout maximamente distribuído - parte 1

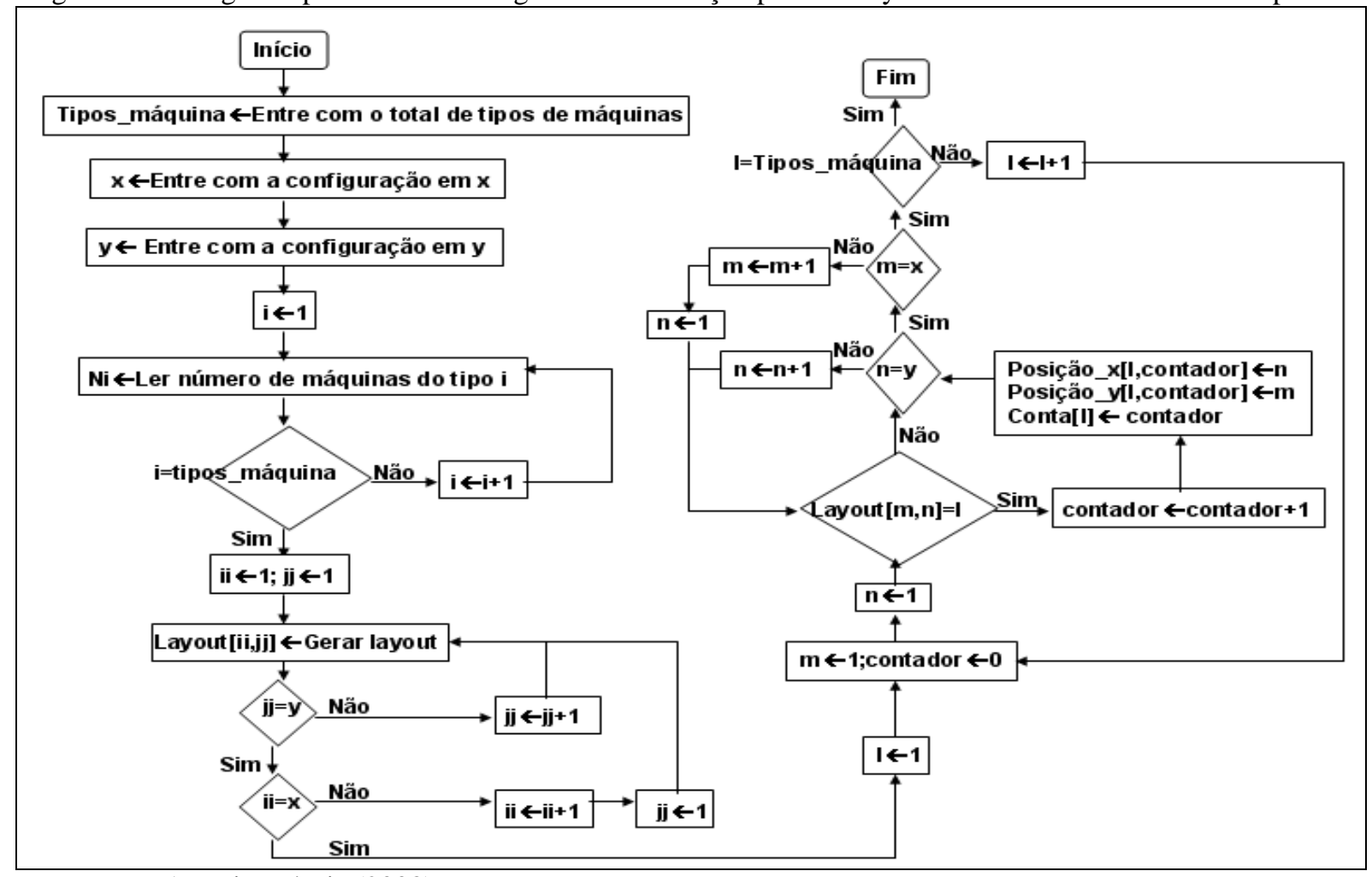

Fonte: Autoria própria (2008) 
Figura 9 - Fluxograma para o cálculo do grau de distribuição para um layout maximamente distribuído - parte 2

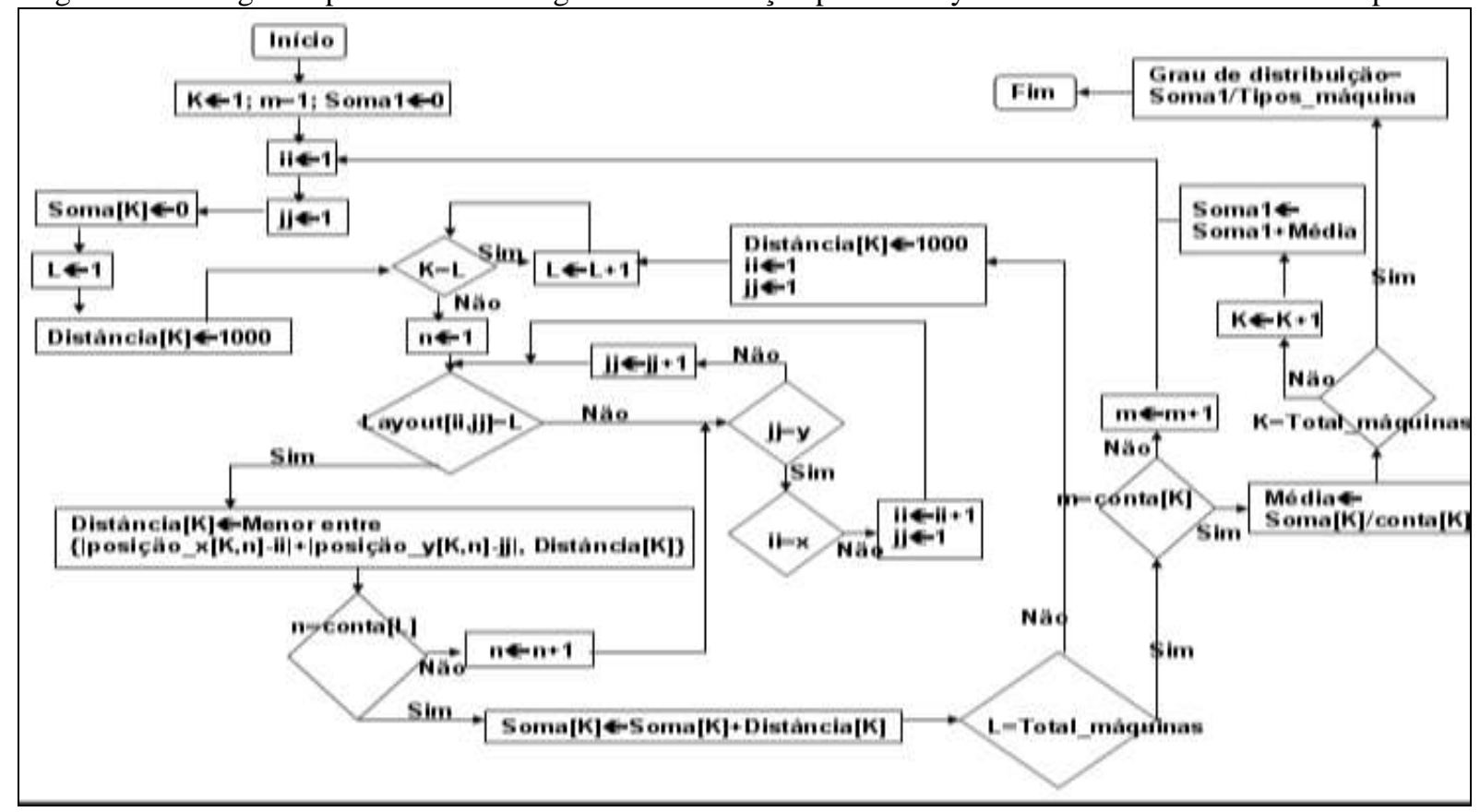

Fonte: Autoria própria (2008)

\section{Dummy Department (vão vazio)}

Dentre os trabalhos sobre layout distribuído, apenas Benjaafar e Sheikhzadeh (2000) comentam sobre dummy department, porém não chegam a lidar com esta questão. Isso porque em sua formulação matemática QAP, uma das restrições é que os locais sejam iguais ao número de máquinas, portanto ignorando a possibilidade de vão vazio. Sabe-se que dependendo do tipo de máquina (principalmente aquela de elevado custo de aquisição), pode não ser possível adquiri-la. A Figura 10 mostra uma situação em que existem 6 locais/espaços e 5 tipos de máquinas (a numeração representa o tipo de máquina). Além das seis posições que o vão vazio pode ocupar, existe também a possibilidade de que as próprias máquinas troquem de posição entre si. É necessário avaliar o desempenho em cada situação e identificar em que posição o vão deve estar e qual máquina deve ocupá-lo. Assim, se houverem n locais e n-1 máquinas, ao todo existem n*(n-1)! possibilidades que é o próprio n!. Em resumo, sob o ponto de vista matemático, vão vazio não deixa de ser um tipo de máquina.

Uma outra forma de representação é deixar todas as máquinas na mesma linha sem vínculo com a configuração do layout. Por exemplo, no primeiro layout da Figura 6, a representação seria 123450, no segundo seria 123045, e assim por diante, onde o vão vazio é representado pelo número 0. 
Figura 10 - Possíveis posições do dummy department
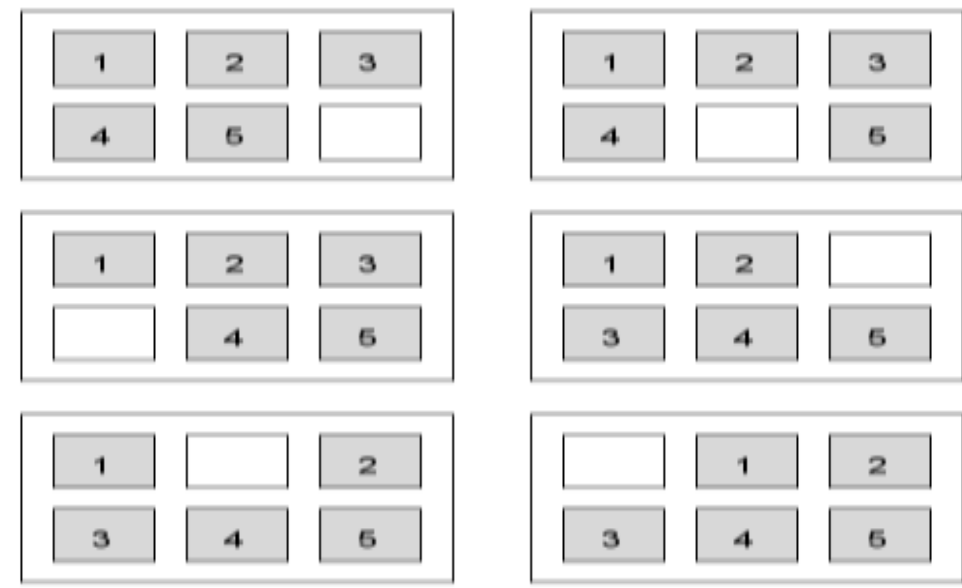

Fonte: Autoria própria (2008)
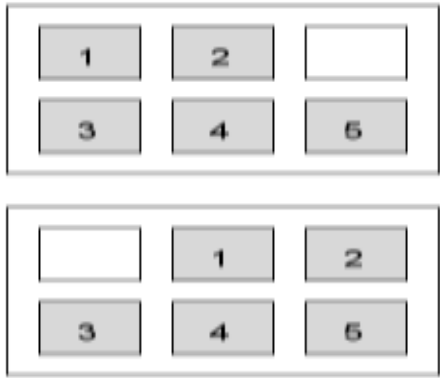

Dependendo do tipo de layout, não se pode inserir o valor "nulo" em qualquer posição porque isso perderia a característica do próprio layout. Por exemplo, nos layouts funcionais e parcialmente distribuídos, a característica principal é justamente o agrupamento de mesmos tipos de máquinas. Quando ocorre a inserção deste valor nulo em qualquer local, pode resultar na separação dos mesmos tipos de máquinas. A Figura 11 mostra dois exemplos de layout funcional com dois tipos de máquinas. Foi escolhido o funcional para demonstração porque é mais fácil de visualizar. Mas conceitualmente a forma de geração é também a mesma para o parcialmente distribuído. A primeira é inserir o valor nulo após o término da inserção dos mesmos tipos de máquinas. Já na segunda, o processo de inserção do valor nulo é feito aleatoriamente. Nota-se que no primeiro caso ainda o layout continua sendo funcional, porém já no segundo, uma das réplicas da máquina 2 está separada do seu grupo.

Figura 11 - Exemplos de layout funcional com separação ou não de máquinas do mesmo tipo inserindo o "nulo"
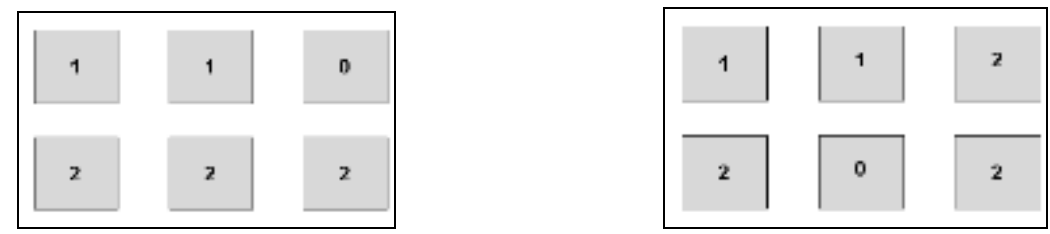

Fonte: Autoria própria (2008)

É possível definir um fluxograma para a inserção do valor nulo para cada layout analisado neste trabalho (funcional, aleatoriamente distribuído, parcialmente distribuído e maximamente distribuído). Nesta lista de layouts, o valor nulo pode estar em qualquer posição, como ocorre para layouts aleatoriamente e maximamente distribuídos, ver Figura 12. Apenas o funcional e o parcialmente distribuído possuem agrupamento de mesmos tipos de máquinas, e portanto a forma de geração destes é diferente dos demais, ver Figura 13. Os fluxogramas de inserção do valor nulo estão apresentados nas Figuras 12 e 13. 
Figura 12 - Fluxograma para a geração das diversas possibilidades da posição nula para os layouts cujas máquinas não possuem relacionamento algum

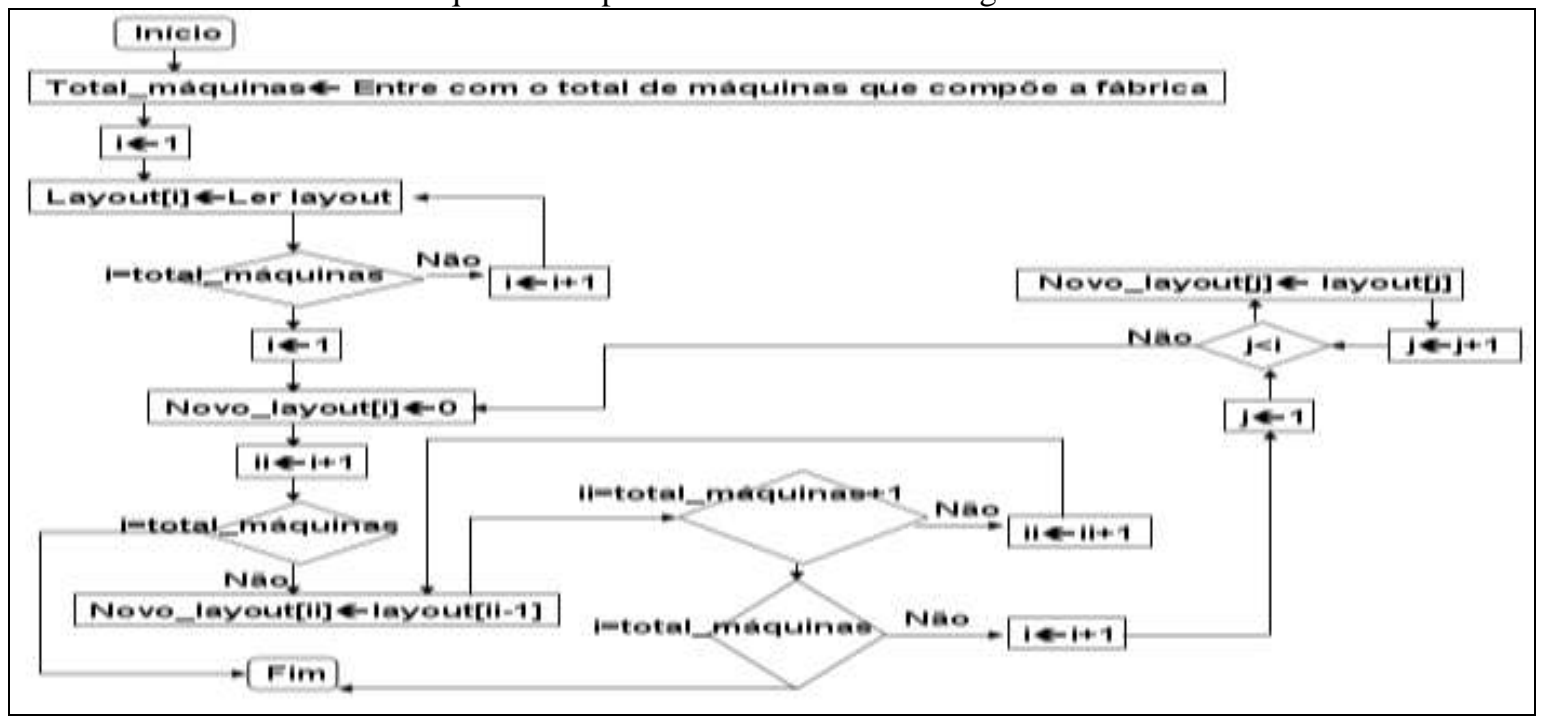

Fonte: Autoria própria (2008)

Figura 13 - Fluxograma para a obtenção das possíveis posições de vão vazio cujas máquinas possuem algum relacionamento

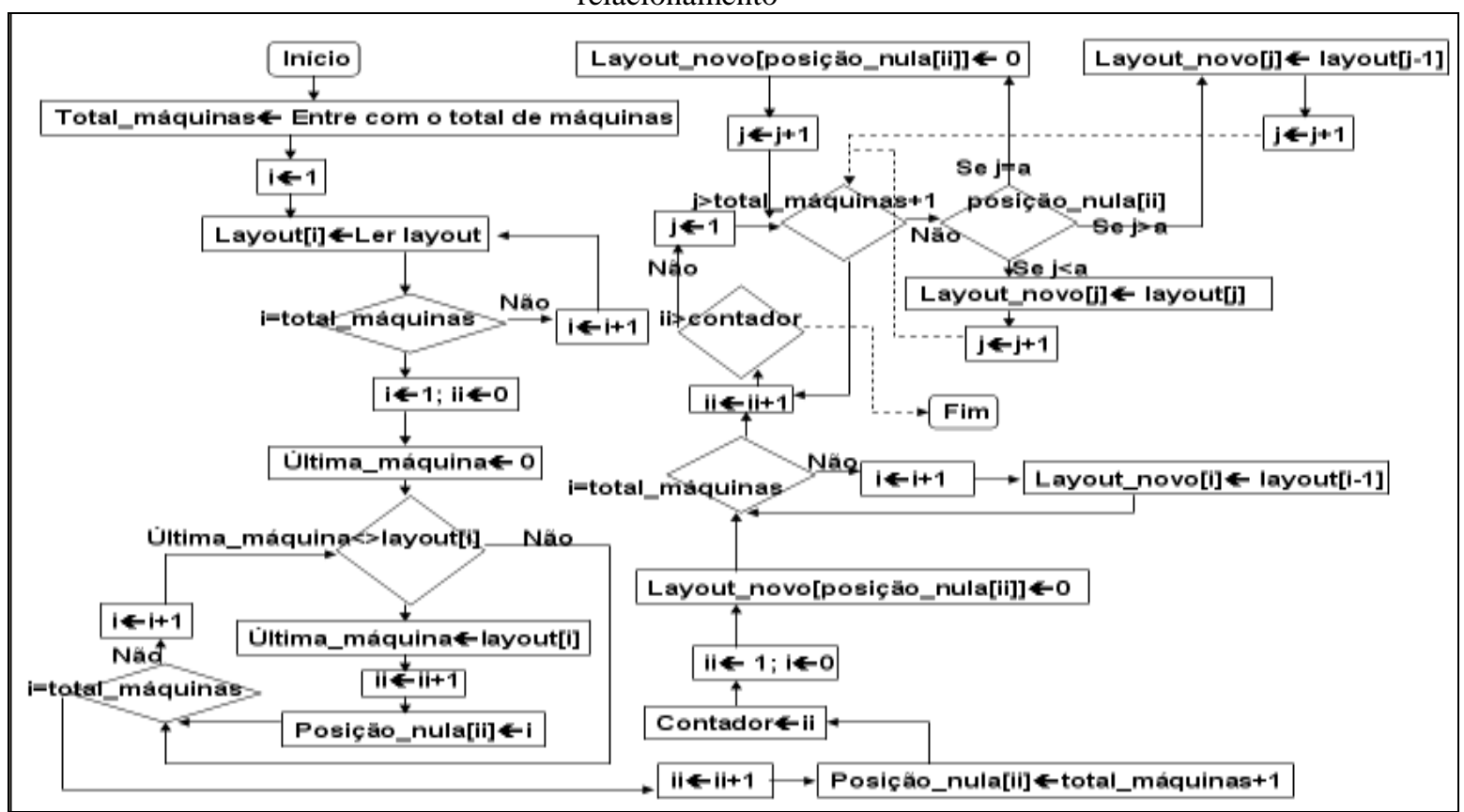

Fonte: Autoria própria (2008)

\section{Alocação de máquinas}

Com o layout gerado (em formato horizontal), a etapa seguinte é alocar máquinas nos locais. A Figura 14 mostra a ordem de preenchimento (de esquerda para direita e de cima para baixo) e é justamente como a linguagem de programação trabalha. Considere que o layout gerado pelo código seja 455326165.

A primeira máquina a ser alocada é a máquina do tipo 4, e em seguida uma outra máquina 4 e assim sucessivamente. 
Figura 14 - Exemplo de alocação de máquinas

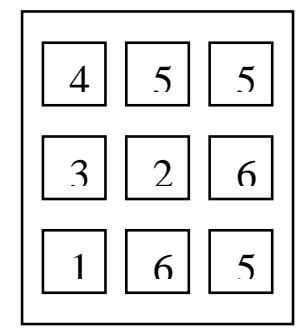

Fonte: Autoria própria (2008)

No entanto este método de alocação já não pode ser aplicado quando existe relação entre os tipos de máquinas, como mostrado anteriormente no caso do vão vazio. É necessário, portanto, um método de alocação (preenchimento) que obedeça os tipos de máquinas.

As curvas de preenchimento espacial ou Peano, propostas por Sagan (1991) ajudam ao projetista em alocar as máquinas no chão de fábrica. Implicitamente o exemplo da Figura 11 (a da esquerda) já está com um tipo de preenchimento, também considerado o mais simples. Este artigo apresenta apenas um fluxograma (ver Figura 15) deste método de preenchimento porque na prática também é mais simples de realizar a implementação. Foi adotado este método porque em comparação aos demais tipos de preenchimento, este permite maior contato de um tipo de máquina em relação aos demais.

Figura 15 - Fluxograma para o preenchimento das máquinas nos locais

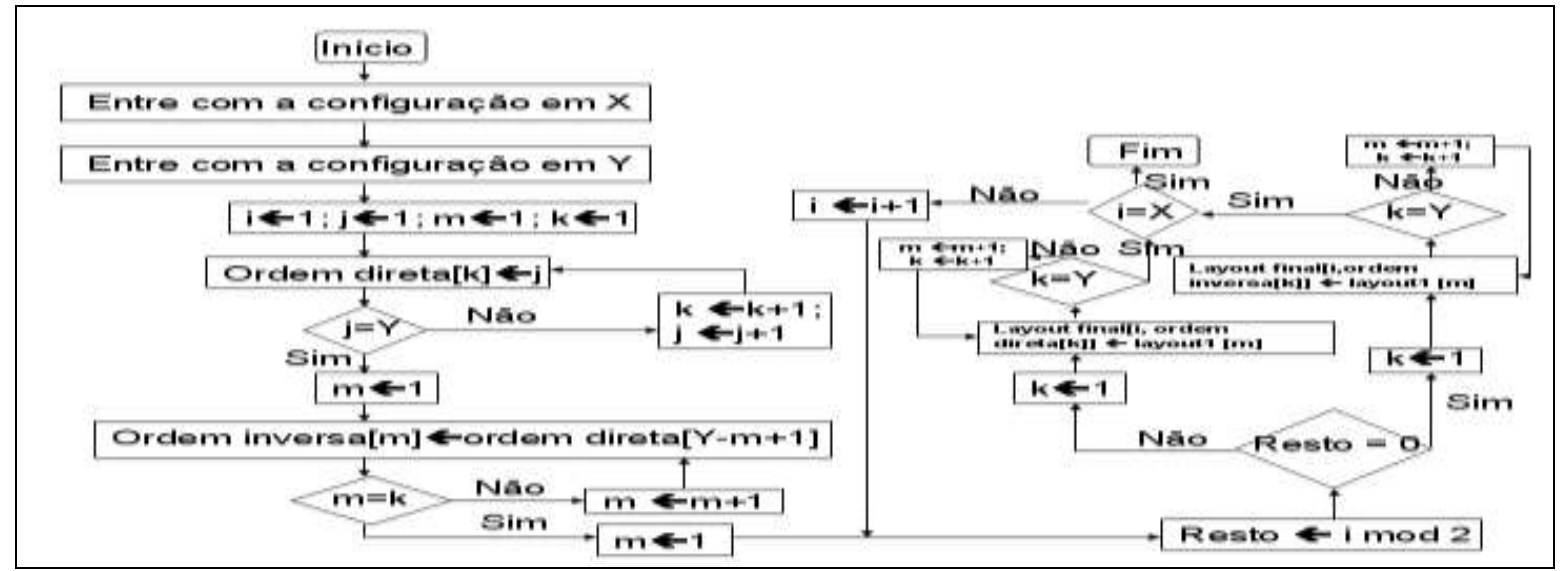

Fonte: Autoria própria (2008)

\section{Descrição sobre o funcionamento da empresa}

Antes de definir como as peças devem percorrer no chão de fábrica e assim obter o tempo de consolidação do pedido, deve-se primeiramente entender como funciona um sistema produtivo e analisar o que afeta diretamente na fabricação da peça. A Figura 16 apresenta a vista superior do chão de fábrica. Independentemente dos formatos que as máquinas podem formar no chão de fábrica, todos possuem uma entrada (Local 1 ou L1) e uma saída (Local 2 ou L2). Os pedidos 
chegam ao Local 1 e é onde os funcionários tipo 1 partem para a entrega da matéria-prima nas máquinas. Já em Local 2 é o destino das peças fabricadas, onde serão embaladas e despachadas. Os funcionários denominados tipo 2 são responsáveis pela produção da peça em si. Os tipo 3 são responsáveis pelo transporte de peças semi-acabadas entre as máquinas e por fim, os tipo 4, localizados em Local 2, ficam encarregados de coletar peças acabadas das máquinas.

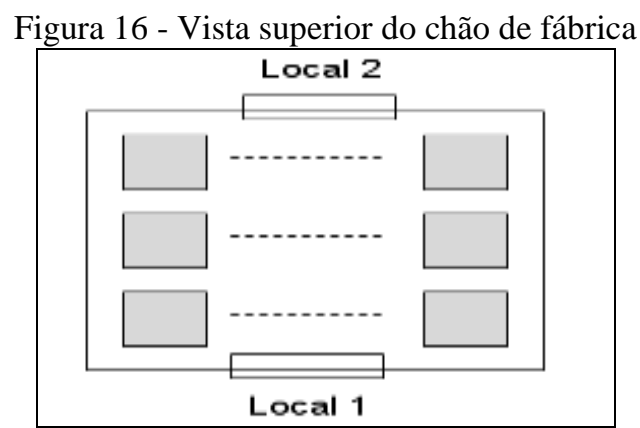

Fonte: Autoria própria (2008)

As informações coletadas dos pedidos em L1 (que neste trabalho foram geradas em computador pelo fluxograma) permite que as matérias-primas das peças sejam montadas, neste mesmo local, no transportador para dar início à entrega nas máquinas. As demandas geradas são na realidade uma lista das peças de cada cliente por dia. A fábrica, portanto, foi previamente projetada para realizar a produção das peças deste conjunto de demanda.

Nas indústrias mecânicas, comumente se usam caixas para armazenamento de peças (sejam elas ainda em estado de matéria-prima, peças semi-acabadas ou recém-fabricadas) e carrinhos manuais para o transporte destas caixas. Adota-se neste trabalho que em uma caixa exista apenas um tipo de peça.

Inicialmente, com os pesos das peças e o tamanho do lote definidos, deve-se criar um fluxograma para separar as matérias-primas a serem transportadas por cada um. Pode ser que mais de um transportador inicial seja usado, porém nunca dois ou mais transportadores são montados simultaneamente em L1 por causa da capacidade de carregamento, ver Figura 17. Isso porque enquanto o primeiro não atingiu a capacidade de carregamento, o segundo nem sequer tem conhecimento das matérias-primas a transportar. O lote de mesmo tipo de peça também não se separa entre os transportadores consecutivos. Dessa forma, quando os dados forem gerados pelo fluxograma, o modelo de simulação tem conhecimento de quando um transportador deve partir para a entrega de matéria-prima como também as matérias primas que este está transportando.

De forma similar, conhecendo as peças a serem produzidas, o funcionário 1 automaticamente tem conhecimento do material em que está carregando e conseqüentemente o tipo de máquina que este deve atingir. Ao chegar na máquina, o lote de matéria-prima da peça que requisita aquela operação é deixada, e assim sucessivamente até que todo transportador é esvaziado. 
Figura 17 - Fluxograma para a separação dos pedidos por transportador

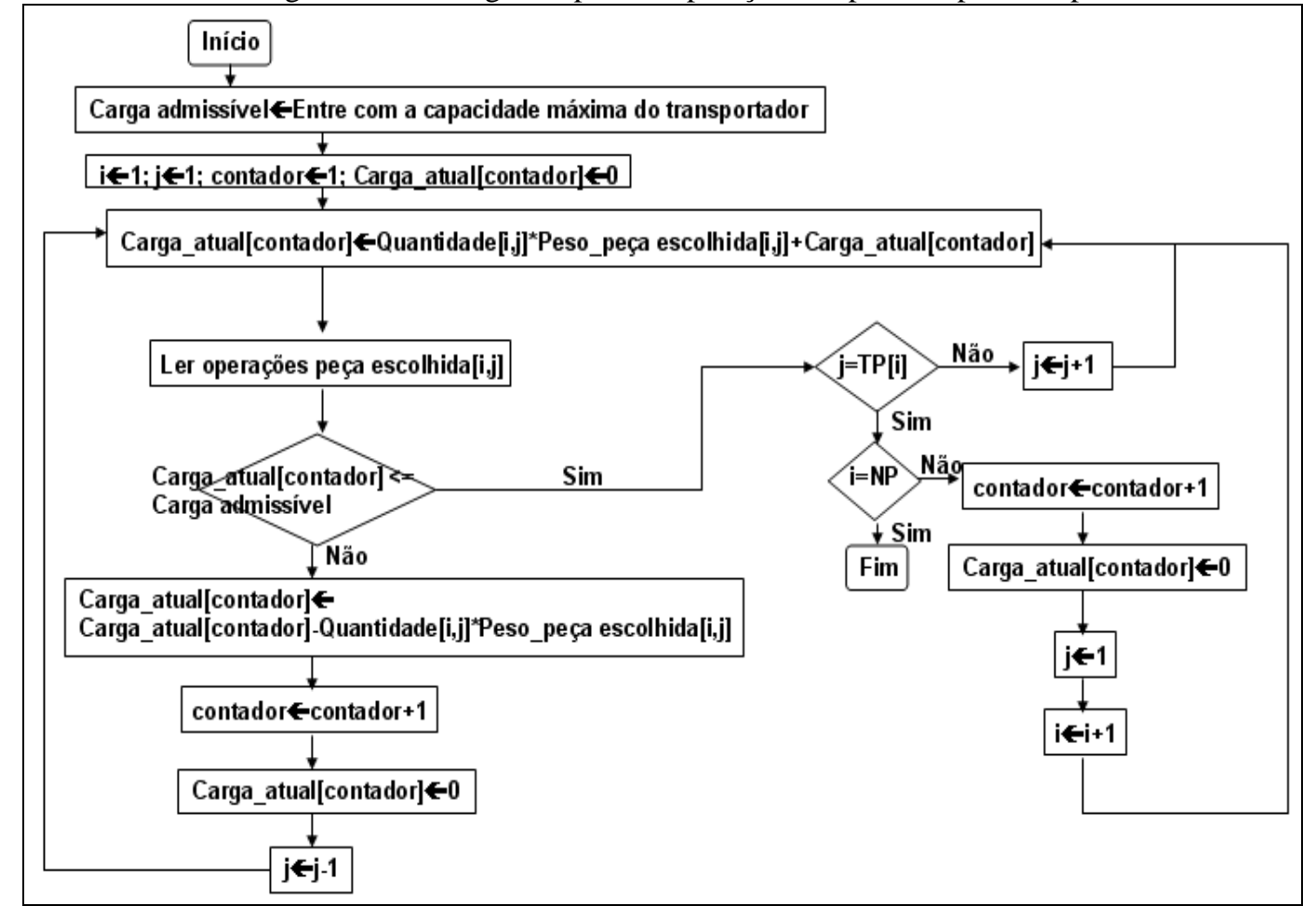

Fonte: Autoria própria (2008)

Na medida em que ocorre o descarregamento, a velocidade aumenta, porque o impacto que é causado pelo peso das peças também diminui. Este impacto também é chamado de fator_V, variando conforme a carga do transportador (ver Shih et al., 2004), ver (2)).

$$
\text { Fator_V }=0,75+0,25\left(\frac{C \arg \text { máximaadmissível }-C \arg a[\mathrm{~kg}]}{C \arg \text { a máximaadmissível }}\right)
$$

Sempre que ocorre uma atualização da carga (através do carregamento ou descarregamento, novo valor do fator_V é obtido. Para obter a velocidade em cada instante, basta multiplicar este fator pela velocidade de descarregamento (ou seja, estado em que o transportador possui maior velocidade por estar descarregado).

Após o processamento nas máquinas, ocorre o transporte entre máquinas. As posições iniciais destes transportadores também devem ser geradas pelos códigos de programação, ver Figura 18. Inicialmente o código solicita ao usuário inserir o número total de transportadores e em seguida o código espalha estes nas máquinas até que não sobre nenhum transportador. Se a mesma posição for escolhida duas ou mais vezes para ser a posição inicial do transportador, então novo local é gerado evitando assim que mais de um transportador esteja na mesma posição. Ou seja, se armazena_valor[i] <>0 significa que o transportador (bem como um funcionário tipo 3) já está alocado na máquina da posição i. Através desta informação das posições iniciais, o modelo faz a leitura do número de transportadores usados, das posições iniciais de todos os transportadores. 
Figura 18 - Fluxograma para a geração das posições iniciais dos transportadores intermediários

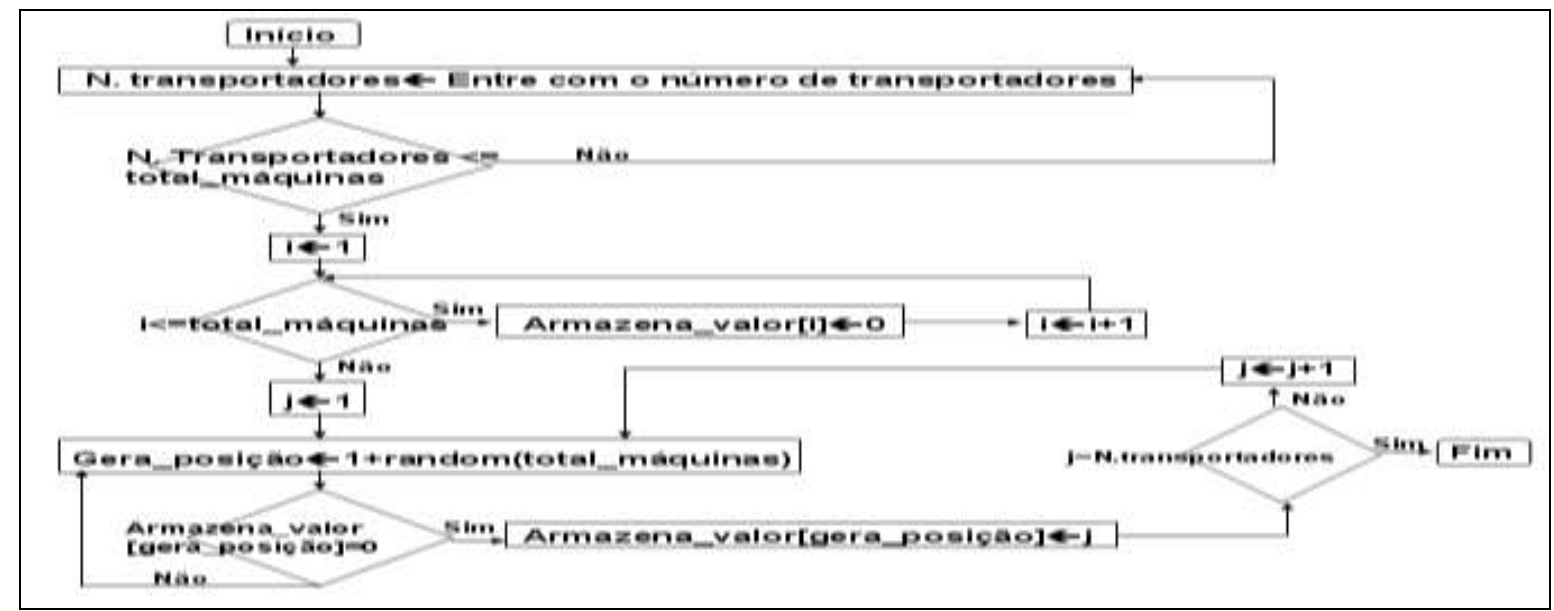

Fonte: Autoria própria (2008)

\section{Recursos envolvidos na produção das peças}

Após a compreensão de funcionamento de uma fábrica, é possível identificar alguns dos recursos mais importantes que afetam diretamente no tempo de consolidação do pedido pois dependendo da forma de como são escolhidos (programação da produção), pode acabar incrementando no tempo total de produção da peça. É importante ressaltar que existe necessidade de se adotar critérios por causa de conflitos no uso de recursos. É possível também identificar basicamente três tipos de filas: "Fila aguardando processamento" formado antes da máquina, "fila de peças semi-acabadas" que se forma após a máquina aguardando transportador trazido por um funcionário 3 e "fila de peças acabadas" que se forma após a máquina aguardando funcionário 4 trazer um transportador.

É impossível analisar os recursos estudando-os separadamente, isso porque existe interação entre eles.

Como dito anteriormente, existem quatro grupos de funcionários que exercem papéis diferentes no chão de fábrica e que lidam diretamente com a peça. São eles: os responsáveis pela montagem e transporte de matéria-prima (funcionário tipo 1), os responsáveis pela produção (tipo 2), os responsáveis pelo transporte de peças semi-acabadas (tipo 3) e por fim transporte de peças recém-fabricadas (tipo 4). Considerou-se neste trabalho que existe um número ilimitado de funcionários em L1, ou seja, toda vez que o sistema tenha separado pedido por carga do transportador, sempre existirá funcionário e até mesmo transportador disponível. Ao chega na máquina, ele descarrega a caixa e a deixa em fila.

A única informação externa necessária para ser lida pelo modelo de simulação é o local de destino dos funcionários, ver Figura 19. Os dados deste fluxograma são usados por todos os funcionários exceto o funcionário 2, porque este é o único que não realiza deslocamentos na fábrica. 
Deve-se lembrar que quando existe alguma relação entre as máquinas, tais como funcional e parcialmente distribuídos, deve-se fazer algumas adaptações em x e em y, porque o preenchimento no chão de fábrica segue uma ordem, ou seja, em vez da variável "layout[i]" (responsável pelo armazenamento das máquinas na horizontal) receber alocações usando fluxograma da Figura 15, deve ser adaptado para que os dados esteja similar ao da Figura 14.

Figura 19 - Fluxograma para a busca do local da máquina requisitada e conversão deste local de destino em x e y (um exemplo), onde "menor" é um valor suficientemente grande

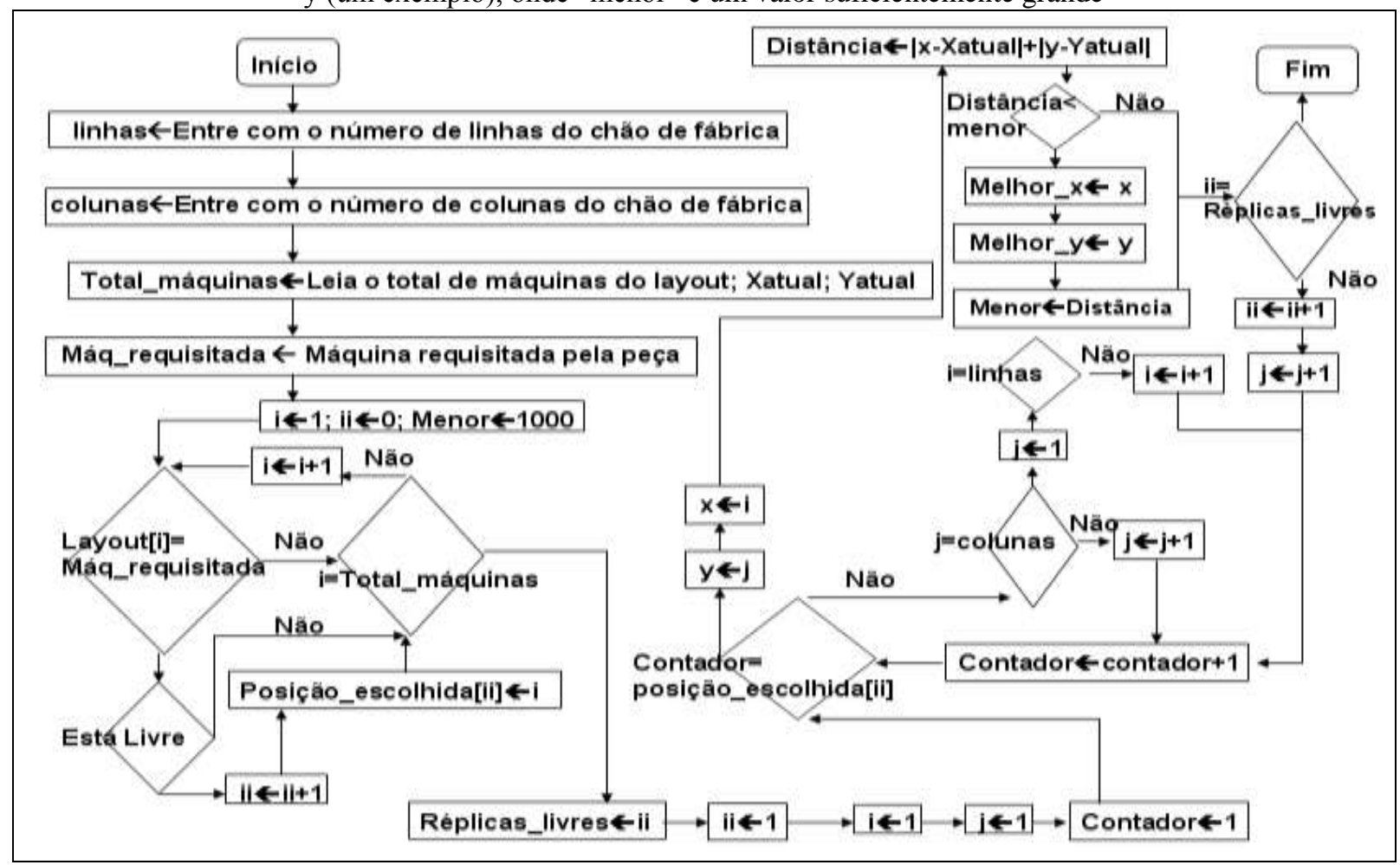

Fonte: Autoria própria (2008)

Para interpretar o fluxograma da Figura 19, considere por exemplo que a matéria-prima da primeira peça tem como primeira operação a máquina 4. Como o layout gerado é de formato horizontal (porque é assim que o modelo de simulação trabalha), este fluxograma deve percorrer este layout e a posição que tiver a máquina 4 na condição de livre deve ser a escolhida. Ao converter para x e y, a distância é assim obtida, fazendo-se $\left|\mathrm{x}_{\text {origem }}{ }^{-} \mathrm{x}_{\text {destino }}\right|+\left|\mathrm{y}_{\text {origem }}-\mathrm{y}_{\text {destino }}\right|$, que é o próprio De-Para. Como pode existir mais de uma máquina 4 livre, escolher a mais próxima. A Tabela 2 ilustra bem este exemplo para um layout $3 \times 3$ na horizontal. Os "estados" representam as situações de ocupado (1) e livre (0).

No exemplo da Tabela, como existe apenas uma máquina 4 livre, então deve-se obter a posição $x=3$ e $y=3$. Se o critério fosse baseado em tamanho de fila, basta percorrer e escolher a desejada. A representação usada na Tabela 2 para o "tamanho fila" serve para todos os tipos de fila. 
Tabela 2 - Exemplo de checagem dos tipos de máquinas e estado delas

\begin{tabular}{|c|c|c|c|c|c|c|c|c|c|}
\hline Layout & 5 & 1 & 3 & 4 & 6 & 2 & 2 & 1 & 4 \\
\hline $\begin{array}{c}\text { Estado } \\
\text { máquina }\end{array}$ & 0 & 1 & 0 & 1 & 0 & 0 & 1 & 1 & 0 \\
\hline $\begin{array}{c}\text { Tamanho } \\
\text { fila }\end{array}$ & 0 & 4 & 0 & 0 & 0 & 0 & 1 & 3 & 0 \\
\hline $\begin{array}{c}\text { Posição x } \\
\text { e y }\end{array}$ & 11 & 12 & 13 & 21 & 22 & 23 & 31 & 32 & 33 \\
\hline
\end{tabular}

Fonte: Autoria própria (2008)

Os funcionários tipo 2 atuam diretamente na produção da peça em si. Além de serem responsáveis em colocar matéria-prima e peças semi-acabadas nas máquinas que estavam em fila, são responsáveis também pela troca de ferramentais. Adotou-se neste trabalho que o número de funcionários seja de igual ao de máquinas, ou seja, cada funcionário fica encarregado em executar a peça naquela sob sua responsabilidade. Caso o número de funcionários fosse menor que o de máquinas, seria necessário adotar critérios de seleção de funcionários analisando, por exemplo, qual funcionário mais próximo da máquina que o requisita ou o primeiro que estiver livre de alguma atividade. Este deslocamento do funcionário de uma máquina à outra acaba incrementando no tempo total de produção da peça. Após o processamento, as peças são recolocadas em caixas. Esta ficam aguardando em fila até a chegada do funcionário 3.

Quanto ao terceiro grupo, é responsável pelo transporte de peças semi-acabadas entre máquinas. Assim que chega na máquina que o requisita, o funcionário 3 faz a coleta das caixas (onde contém as peças semi-acabadas) e as põe no transportador. As posições que eram de destino da Figura 19 passam a ser de origem e então faz a entrega na máquina seguinte (novas posições de destino). Adotou-se nesse trabalho que o transportador apenas carrega uma caixa por vez.

E por fim, o quarto grupo de funcionários está localizado no L2. Estes são só solicitados quando existem peças recém-fabricadas nas máquinas. Quando esta condição é verdadeira, eles partem para a coleta das peças. Semelhantemente ao primeiro grupo, existe também um número ilimitado de funcionários. A condição de partida entre os funcionários é que quando a capacidade do transportador tenha sido atingida, um outro imediatamente sai de L2 antes mesmo do anterior retornar ao L2, mas nunca dois ou mais atuam na coleta simultaneamente.

A matéria-prima também não deixa de ser um recurso usado pela empresa. Ela é transformada à medida que percorre no chão-de-fábrica, saindo de L1. Considerou-se que não existe falta de matéria-prima a ser usada em fabricação de peças.

Todas as máquinas da fábrica trabalham com blocos de ferramentas. Neste bloco, existem um conjunto de ferramentas acopladas à ele. Assim quando a peça requisita um ferramental que já exista neste bloco, simplesmente não existe tempo referente à troca de ferramental. Caso contrário, deve-se fazer a montagem do requisitado no bloco. A Tabela 3 mostra um exemplo de layout contendo duas máquinas e quatro ferramentais cada. Note que em cada máquina os ferramentais não 
se repetem. É necessário agora fazer a checagem se existe necessidade de fazer setup, como mostrado no fluxograma da Figura 20. No caso, a variável i=4 porque a capacidade do bloco é de armazenar 4 ferramentas de uma só vez.

Tabela 3 - Exemplo de layout com duas máquinas e seus respectivos blocos de ferramentas

\begin{tabular}{|c|c|c|c|c|c|c|c|c|}
\hline Layout & \multicolumn{3}{|c|}{5} & \multicolumn{4}{|c|}{1} \\
\hline Ferramental & 5 & 2 & 1 & 4 & 2 & 7 & 3 & 1 \\
\hline
\end{tabular}

Fonte: Autoria própria (2008)

Figura 20 - Fluxograma para a checagem e efetuação de setup de ferramental

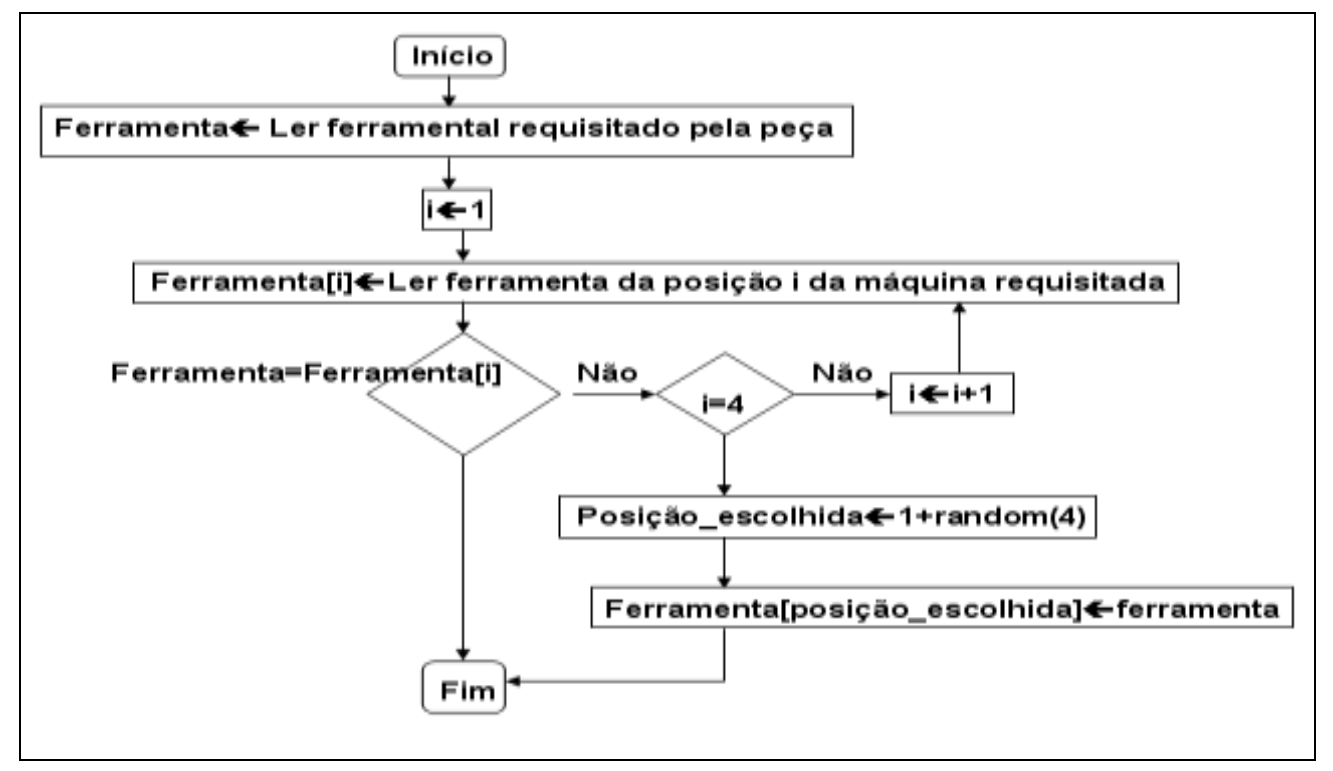

Fonte: Autoria própria (2008)

Pode-se usar o critério de seleção das máquinas baseado nas trocas de ferramentais. Inicialmente o modelo de simulação checa as ferramentas de todas as réplicas de uma determinada máquina, e escolhe a que não necessitar fazer trocas de ferramentas porque a ferramenta que uma determinada peça requisita já está acoplada à ela. Porém, de acordo com Ham et al. (1985), o tempo de setup não é um componente crítico do tempo total de produção da peça, mas sim apenas o tempo de deslocamento e espera em fila.

Com relação ao recurso máquinas, as réplicas do mesmo tipo são idênticas na sua forma de processar, ou seja, nenhuma se diferencia na sua velocidade de processamento. Não será considerada quebra de máquina, porque julgou-se que isso faz parte da manutenção.

E por fim, com relação aos transportadores, existem três tipos executando tarefas distintas no chão de fábrica, porém em nada difere fisicamente um do outro. Estes são empurrados pelos funcionários tipos 1,3 e 4 . 


\section{Critérios adotados}

A literatura apresenta vários critérios possíveis de serem trabalhados, ver por exemplo Gupta (1999), Subramaniam et al. (2000) e Sawik (1995). Não é papel deste trabalho implementar todos os critérios apresentados, mas antes faz-se uma análise criteriosa e escolher os mais adequados.

Julgou-se adequado ao funcionário 2 retirar peça em fila para o processamento baseada naquela que chegou primeiro, ou seja, FIFO (First In-First Out). FIFO também será aplicado para transportadores que conduzem peças semi-acabadas em fila, assim o funcionário 3 retira peça de uma determinada máquina conforme a ordem de chegada dela em fila. Ainda com relação ao funcionário 3, existe disputa entre máquinas para chamá-lo, ou seja, antes de fazer carregamento de peças semi-acabadas, é necessário a locomoção dele até ela. Existem duas possibilidades: A primeira é aquele que ficar disponível, então vai imediatamente à máquina. Caso houverem dois ou mais transportadores, deve-se escolher a que estiver mais próximo da máquina que o requisitou (lembrando que o funcionário 3 sempre está junto com o seu transportador).

Após o carregamento, os funcionários 1 e 3 necessitam transportar peças às máquinas. Existem duas situações que as máquinas podem ser encontradas: Livre ou ocupada. Na primeira, se houver apenas uma máquina disponível, a peça é imediatamente conduzida a ela. Se houverem mais de uma disponível, deve-se escolher a que estiver mais próxima. Já na segunda situação, uma das possibilidades é que a peça aguarde até que uma das réplicas da máquina fique livre. Outra possibilidade para a segunda situação é que a peça é conduzida pelo transportador, mesmo a máquina ainda estando ocupada, à réplica que tenha a menor fila. Ou então, ser conduzida à máquina mais próxima.

E quanto ao funcionário 4, existem algumas possibilidades de escolher as máquinas para os transportadores que saem do Local 2 (ou da última coleta onde se encontra). Quando apenas uma máquina possui fila de peças acabadas, então não existe disputa e portanto o transportador só tem que se deslocar até ela. Se houverem mais de uma máquina, deve-se adotar critérios, porque existe disputa. A primeira é fazer com que o modelo faça uma análise dos tamanhos de filas que se formam de peças recém-fabricadas (similar à Tabela 2). Escolher sempre o maior. Caso haja mais de uma máquina com o mesmo tamanho de fila, escolher a mais próxima dele. Uma outra é a mais próxima e caso houver empate, escolher a de maior fila.

As Figuras 21 a 25 ilustram resumidamente os critérios adotados neste trabalho e que dependendo da forma de como são combinados, afetam o desempenho do sistema. 
Figura 21 - Máquina Disponível (MD)

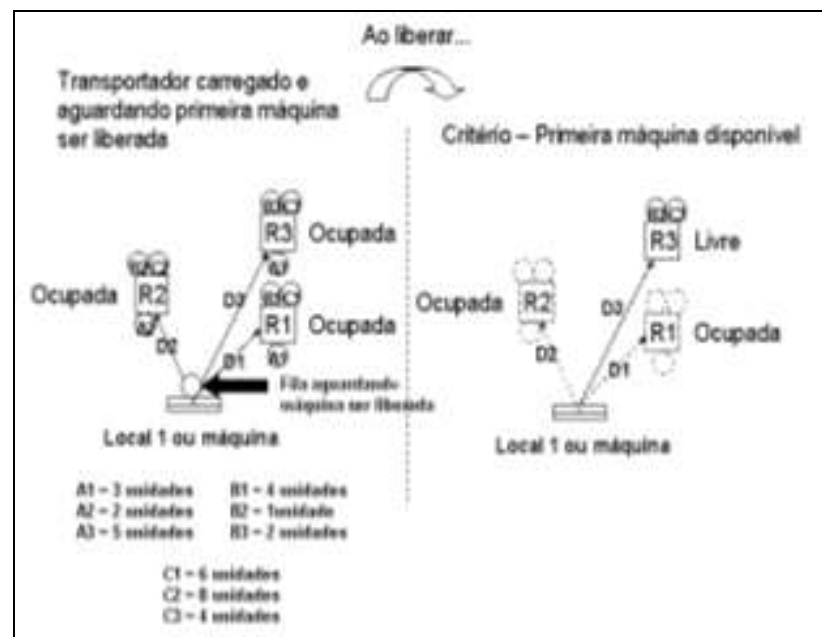

Fonte: Autoria própria (2008)
Figura 22 - Máquina mais Próxima (MP)

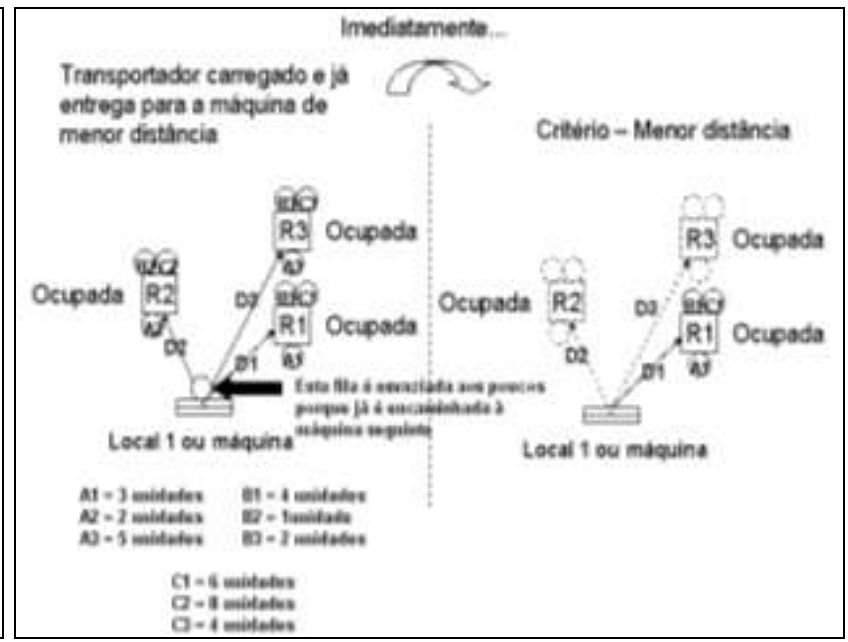

Fonte: Autoria própria (2008)

Figura 23 - Máquina de menor Fila (MF)

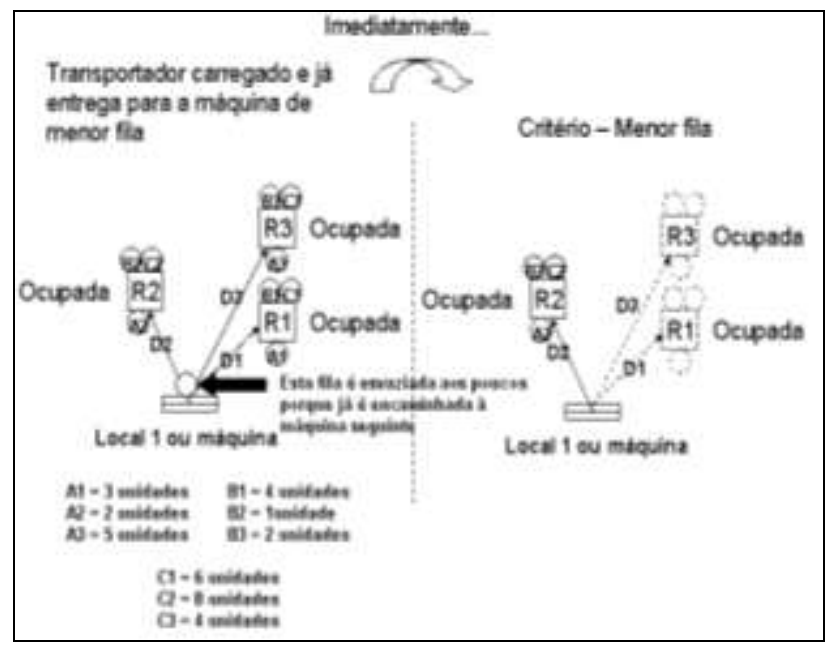

Fonte: Autoria própria (2008)

Figura 24 / Figura 25 - Maior Fila e Menor Distância (MFMD) / Menor Distância e Maior Fila (MDMF)

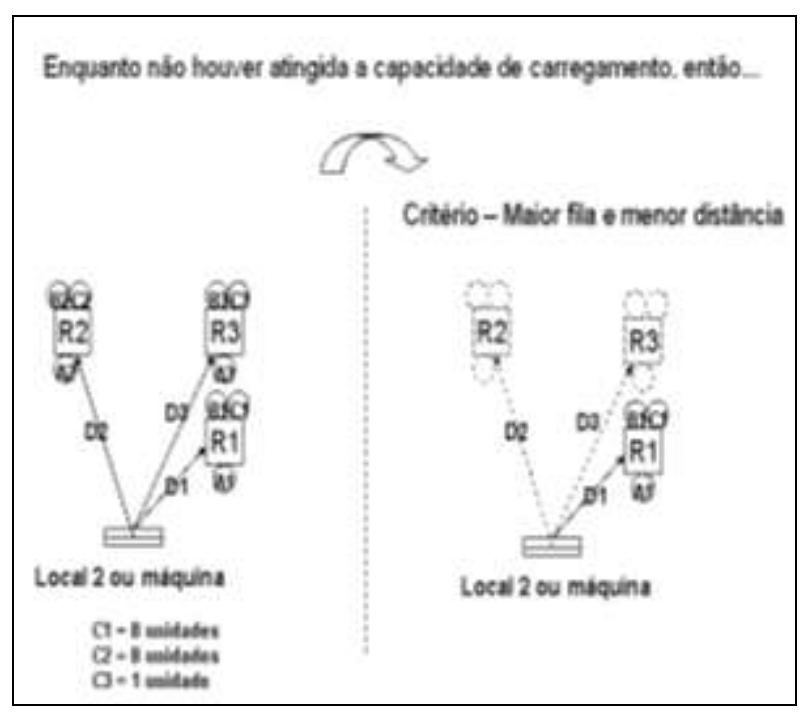

Enquarto njo houser atingida a capacidade de carregamento. entio -

$\mathrm{Com} 02=03$

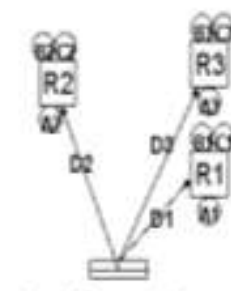

Local 2 ou miquina

Cr-B mildete

Q-1 midioter

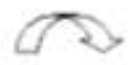

Crtério - Menor distancia e maior fila

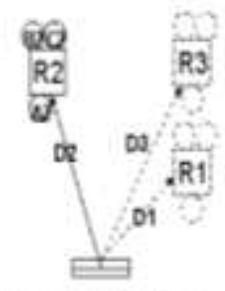

Locas 2 ou miquina

Fonte: Autoria própria (2008) 
Para testar os critérios, a etapa seguinte é descrever alguns dados numéricos de entrada ao modelo de simulação e os resultados serão comparados entre si. O melhor critério bem como o melhor layout pode então ser obtido.

\section{Dados de entrada para o modelo de simulação e resultados obtidos}

Para a execução do modelo de simulação, alguns dados de entrada devem ser considerados. Todas as peças não possuem mais do que 10 processos. Cada processo varia de 1 a 100s. Ao todo existem 30 tipos de máquinas. Os pesos das peças variam de peças muito leves (tendendo a zero) até $10 \mathrm{~kg}$. Os lotes considerados variam de unidade a lote de tamanho 3. A velocidade descarregada do transportador considerou-se como uniforme $(0,75 ; 1 ; 1,25) \mathrm{m} / \mathrm{s}$. Todas as máquinas trabalham com blocos de ferramentas. Nestes blocos têm a capacidade de acoplar 4 ferramentais (das nove ferramentas que a empresa trabalha) de uma só vez. Assim, quando uma peça solicita esta ferramenta que não esteja neste bloco, faz-se o setup. O tempo de setup considerado é de 60 s. O carregamento e descarregamento das peças nos transportadores e nas máquinas foram adotados como sendo 5s. Cada caixa é capaz de armazenar $30 \mathrm{~kg}$ independente do volume das peças. A fábrica recebe, em média, pedidos de 20 clientes por dia para serem processados no dia seguinte ao recebimento, sendo que em cada pedido existem 40 tipos de peças. Todos os transportadores usados, seja inicial, intermediário ou final possuem capacidades de transportar 60kg. Foram considerados inicialmente que existam 10 transportadores espalhados nas máquinas, os quais são empurrados pelos funcionários tipo 3 .

Com estas informações de entrada e aplicando os fluxogramas apresentados neste trabalho, dimensionou-se um total de 41 máquinas.

A Tabela 4 apresenta todas as 18 possíveis combinações dos critérios adotados neste trabalho. As Tabelas 5 a 7 mostram os resultados de desempenho em tempo de consolidação do pedido (em segundos) para as 18 combinações possíveis (portanto são 18 linhas para cada Tabela), por layout, por configuração para o layout de tamanho 42 (existindo 6 configurações e portanto 6 Tabelas), com 41 máquinas. As configurações de layout são: 42x1; 2x21; 6x7; 7x6;21x2 e 1x42.

Quanto à coleta de dados, para cada tipo de layout, por configuração, (exceto o maximamente distribuído) foi gerado 50 amostras e assim ao submeterem-se aos critérios de seleção de recursos, as médias são então calculadas e preenchidas nas nessas tabelas.

Os resultados mostram que em geral o funcional apresenta tempos maiores para a consolidação dos pedidos (em segundos). No lado oposto está o maximamente distribuído. Dependendo do critério escolhido e da configuração escolhida, um layout funcional pode ter 
melhores desempenhos que um maximamente distribuído, tais como visto em MF, MP, MDMF para a configuração $6 \times 7$.

Em média, a configuração similar a um quadrado apresenta melhores resultados. Mas um layout bem retangular também pode ter um desempenho tão bom quanto a de um quadrado, dependendo, portanto, do tipo de layout e do critério aplicado.

Como os perfis de pedido simulados são de demanda diária, tem-se por dia $24 * 3600=86400$ s, significa que a fábrica tem que finalizar os pedidos abaixo deste tempo (desconsiderando quaisquer quebras de máquinas, transportadores, etc.., o que aumentaria os tempos). Conforme os resultados apresentados, nem todos os layouts podem ser empregados. Se esse for o limitante, todos os resultados obtidos do maximamente distribuído podem ser usados, porque todos os resultados estiveram abaixo de 86400s. Ainda com relação à este tempo limite, pode-se dizer, com relação ao aleatoriamente e parcialmente distribuídos, que ambos os desempenhos se intercalam, ou seja, alguns podem ser escolhidos na produção enquanto outros não, dependendo do critério usado.

Considere por exemplo que o decisor tenha escolhido para trabalhar com layout aleatoriamente distribuído, de configuração 21x2, sob os critérios MD-MP-MDMF, o que resultou 67158s (abaixo de 86400s) e é também o menor resultado para este mesmo tipo de layout. Essa seria uma boa opção de escolha, mas ao executar o fluxograma da Figura 12 (tendo portanto 42 posições de vão vazio), para os mesmos critérios, o menor pode atingir 66456s.

Tabela 4 - Possíveis combinações dos critérios adotados neste artigo

\begin{tabular}{|c|c|c|c|c|c|c|c|}
\hline \multicolumn{3}{|c|}{ Transportador Inicial } & \multicolumn{3}{c|}{ Transportador Intermediário } & \multicolumn{2}{c|}{ Transportador Final } \\
\hline Tipos de critério & \multicolumn{2}{c|}{ Tipos de critério } & \multicolumn{2}{c|}{ Tipos de critério } \\
\hline MD & - & - & MD & - & - & MFMD & - \\
\hline MD & - & - & MD & - & - & - & MDMF \\
\hline MD & - & - & - & MP & - & MFMD & - \\
\hline MD & - & - & - & MP & - & - & MDMF \\
\hline MD & - & - & - & - & MF & MFMD & - \\
\hline MD & - & - & - & - & MF & - & MDMF \\
\hline- & MP & - & MD & - & - & MFMD & - \\
\hline- & MP & - & MD & - & - & - & MDMF \\
\hline- & MP & - & - & MP & - & MFMD & - \\
\hline- & MP & - & - & MP & - & - & MDMF \\
\hline- & MP & - & - & - & MF & MFMD & - \\
\hline- & MP & - & - & - & MF & - & MDMF \\
\hline- & - & MF & MD & - & - & MFMD & - \\
\hline- & - & MF & MD & - & - & - & MDMF \\
\hline- & - & MF & - & MP & - & MFMD & - \\
\hline- & - & MF & - & MP & - & - & MDMF \\
\hline- & - & MF & - & - & MF & MFMD & - \\
\hline- & - & MF & - & - & MF & - & MDMF \\
\hline
\end{tabular}

Fonte: Autoria própria (2008) 
Tabela 5 - Possíveis combinações dos critérios adotados neste artigo (Continuação da Tabela 4)

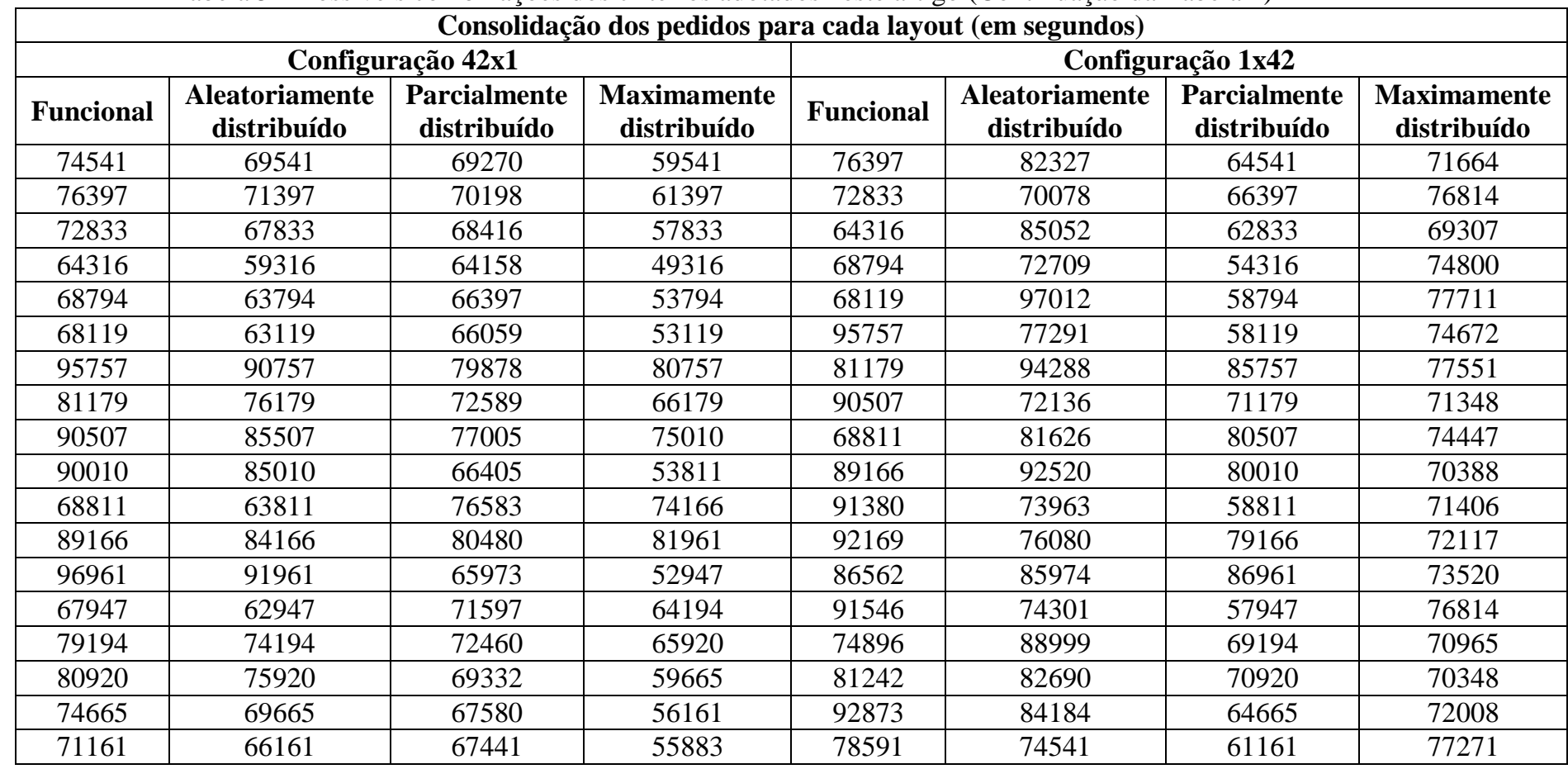

Fonte: Autoria própria (2008)

Tabela 6 - Possíveis combinações dos critérios adotados neste artigo (Continuação da Tabela 4)

\begin{tabular}{|c|c|c|c|c|c|c|c|}
\hline \multicolumn{8}{|c|}{ Consolidação dos pedidos para cada layout (em segundos) } \\
\hline \multicolumn{4}{|c|}{ Configuração 7x6 } & \multicolumn{4}{|c|}{ Configuração 6x7 } \\
\hline Funcional & $\begin{array}{c}\text { Aleatoriamente } \\
\text { distribuído }\end{array}$ & $\begin{array}{l}\text { Parcialmente } \\
\text { distribuído }\end{array}$ & $\begin{array}{c}\text { Maximamente } \\
\text { distribuído }\end{array}$ & Funcional & $\begin{array}{c}\text { Aleatoriamente } \\
\text { distribuído }\end{array}$ & $\begin{array}{l}\text { Parcialmente } \\
\text { distribuído }\end{array}$ & $\begin{array}{l}\text { Maximamente } \\
\text { distribuído }\end{array}$ \\
\hline 78362 & 67270 & 68635 & 78947 & 74574 & 69122 & 68745 & 61179 \\
\hline 78919 & 68198 & 69099 & 69997 & 72365 & 68966 & 66602 & 62478 \\
\hline 77850 & 66416 & 68208 & 68281 & 78069 & 74073 & 72240 & 59983 \\
\hline 75294 & 62158 & 66079 & 68283 & 72147 & 68314 & 66998 & 54021 \\
\hline 76638 & 64397 & 67198 & 61561 & 71128 & 67368 & 65647 & 57155 \\
\hline 76435 & 64059 & 67029 & 64508 & 75684 & 70806 & 69602 & 56683 \\
\hline 84727 & 77878 & 73939 & 54507 & 83048 & 79744 & 77433 & 76030 \\
\hline 80353 & 70589 & 70294 & 61281 & 76001 & 72652 & 70664 & 65825 \\
\hline 83152 & 75253 & 72626 & 68764 & 71726 & 67719 & 65482 & 72355 \\
\hline 83003 & 75005 & 72502 & 63893 & 82456 & 77345 & 75140 & 72007 \\
\hline 76643 & 64405 & 67202 & 67959 & 85332 & 80007 & 78639 & 57167 \\
\hline 82750 & 74583 & 72291 & 67038 & 75451 & 71994 & 69009 & 71416 \\
\hline 85088 & 63973 & 74240 & 60080 & 82284 & 77225 & 75630 & 76873 \\
\hline 76384 & 70460 & 66986 & 70265 & 85004 & 80447 & 78882 & 56562 \\
\hline 79758 & 67332 & 69798 & 68541 & 78677 & 74266 & 72041 & 64436 \\
\hline 80276 & 65580 & 70230 & 59410 & 67310 & 70409 & 68332 & 65644 \\
\hline 78399 & 65441 & 68666 & 74789 & 74413 & 71001 & 69281 & 61265 \\
\hline 77348 & 79722 & 67790 & 69137 & 75718 & 65808 & 75002 & 58813 \\
\hline
\end{tabular}

Fonte: Autoria própria (2008)

Tabela 7 - Possíveis combinações dos critérios adotados neste artigo (Continuação da Tabela 4) Consolidação dos pedidos para cada layout (em segundos) 


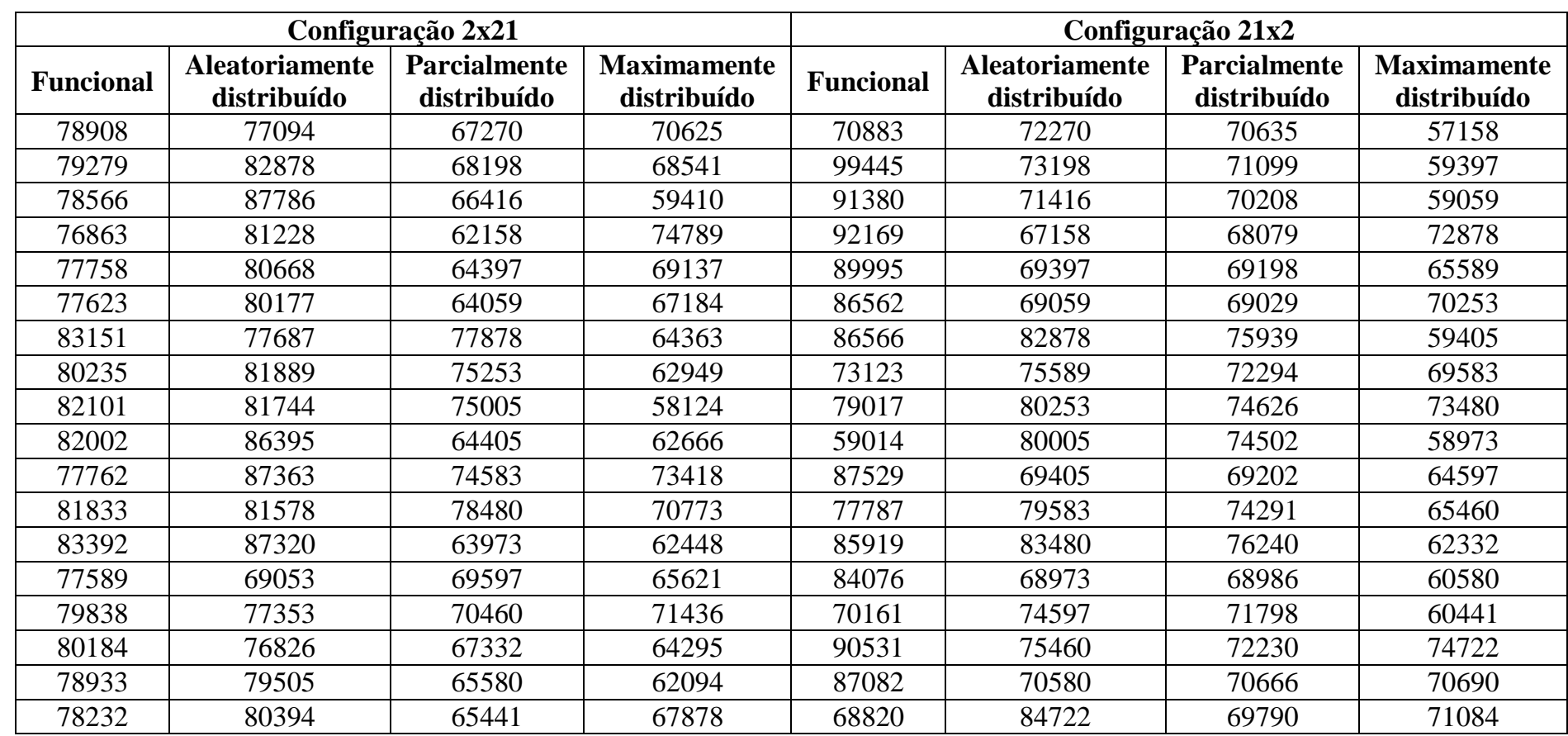

Fonte: Autoria própria (2008)

\section{Conclusão}

Os artigos da literatura apresentam estudos de desempenho (baseados em fluxo entre máquinas), mas não comentam como as peças foram geradas, como os layouts são gerados, como as máquinas são espalhadas, como os transportadores são separados, de como faz a checagem das situações das máquinas, como as peças devem percorrer no chão de fábrica, etc.. Com este trabalho, dados podem ser gerados para fins de estudo e podem ser implementados em qualquer código de programação. Além disso, considerou-se na literatura que já exista prontamente a informação do número de réplicas de cada máquina e a configuração do chão de fábrica, mas quando se for fazer um real estudo, nem sempre estas informações estão disponíveis e, portanto, necessitam ser avaliadas e geradas.

Este artigo apresenta fase a fase as etapas e dificuldades encontradas para o desenvolvimento de um layout job-shop. Avaliou-se critérios de seleção de recursos, comparando os desempenhos dos layouts baseados em tempo de consolidação do pedido (diferente do que vinha sendo abordado na literatura, que considerava apenas deslocamento e sem levar em consideração critérios de seleção de recursos). Lembrando que usando parâmetro de desempenho tempo de consolidação do pedido é muito mais amplo que fluxo entre máquinas. Além disso, uma das razões pela qual a literatura não lida com critérios de seleção de recursos é a necessidade de trabalhar com programação da produção. Isso não pode ser feito pelo método tradicional, seja por equações, ou por códigos de programação porque desconsideram as concomitâncias de atividades pelo uso de recursos e variáveis que se alteram ao longo do tempo, tais como tamanho de filas. 
Com base nesse estudo, pode-se concluir que o desempenho é influenciado pela configuração do chão de fábrica que adotar. Isso quer dizer que resultados dos artigos da literatura devem ser revistos porque muitos fixam as configurações dos layouts para assim avaliarem o desempenho, mas a configuração adotada para análise nem sempre é a melhor. O desempenho também é influenciado pelas posições do vão vazio, podendo tanto melhorar ou piorar quando ignoradas.

Dependendo do critério de seleção adotado, um layout funcional pode até ser melhor que um layout maximamente distribuído. Isso quer dizer que a melhoria de desempenho de um layout não está vinculada apenas no espalhamento das máquinas, mas também na questão operacional, pois este último foi mostrado que exerce um papel muito importante.

\begin{abstract}
Due to the necessity to realize a layout research aiming at improving a real company, information such as layout configuration and total number of machines are known. On the other hand, it need to be generated from the demand. This paper aims to present, in details, several steps involved in a job-shop layout design, considering that it does not exist, and discusses some difficulties, several possibilities of layout configuration and dummy-department formation. This paper initially presents bibliography review and then, several flowcharts from data generation to be used in each step of layout design. To evaluate the layout performance, some resources selection criteria is chosen and embedded in simulation model Colored Petri Net. Results are compared among them. The conclusion suggests literature results need to be re-evaluated.
\end{abstract}

Key-words: job-shop development, generating and treating data, system performance, simulation.

\title{
Referências
}

BENJAAFAR, S. Design of flexible layouts for manufacturing systems. In: 95 ENGINEERING MANAGEMENT CONFERENCE, IEEE, 1995.

BENJAAFAR, S. Design of manufacturing plant layouts with queueing effects. In: PROCEEDINGS OF THE 1998 IEEE, International Conference on Robotics \& Automation, Leuven, Belgium, 1998.

BENJAAFAR, S.; SHEIKHZADEH, M. Design of flexible plant layouts. IIE Transactions, vol. 32, p. 309-322, 2000.

\section{cross ${ }^{\text {ref }}$}

JÚNIOR, J. H. C. G.; FILHO, E. V. G. Análise de desempenho dos arranjos físicos distribuídos operando sob roteamento de peças com flexibilidade de sequenciamento. Revista Gestão Industrial, v. 3, n. 1, p. 01-12, 2007.

FRANCIS, R. L.; WHITE, J. A. Facility layout and location and analytical approach. New Jersey: Englewood Cliffs - Prentice-Hall International Series in Industrial and Systems Engineering, 1974.

GUPTA, J. N. D. Part dispatching and machine loading in flexible manufacturing systems using central queues. International Journal of Production Research, v. 37, n. 6, p. 1427-1435, 1999.

cross ${ }^{\text {ref }}$

HAM, I.; HITOMI, K.; YOSHIDA, T. Group Technology - Applications to production management. The Pennsylvania State University: International Series in Management Science/Operations Research, 1985.

JÚNIOR, J. H. C. G.; FILHO, E. V. G. Análise do desempenho dos arranjos físicos distribuídos operando sob roteamento de peças com flexibilidade de sequenciamento. Revista Gestão Industrial, v. 3, n. 1, p. 01-12, 2007. 
LAHMAR, M.; BENJAAFAR, S. Design of distributed layout. IIE Transactions, v. 37, p. 303-318, 2005.

cross ${ }^{\text {ref }}$

MONTREUIL, B.; VENKATADRI, U.; LEFRANÇOIS, P. Holographic layout pf manufacturing systems. $19^{\text {th }}$ IIE Systems Integration Conference, Orlando, Flórida, 1991.

NETO, A. R. P.; CHIN., S. Y.; FILHO, E. V. G. Design of distributed layouts with operational efficiency considerations. In: $19^{\text {th }}$ INTERNATIONAL CONFERENCE ON PRODUCTION RESEARCH. Valparaiso, Chile: $19^{\text {th }}$ ICPR, 2007.

SAGAN, H. Space-filling curves. New York: Springer-Verlag, 1991.

SAWIK, T. Dispatching scheduling of machines and vehicles in a flexible manufacturing system. In: PROCEEDINGS OF EMERGING TECHNOLOGIES AND FACTORY AUTOMATION, v. 2, p. 3-13, 1995.

SHIH, Y. C.; JÚNIOR, J. H. C. G.; NONATO, S.; PORTO, A. J. V. Desbalanceamento do número de itens das listas de coleta para reduzir o tempo do processo de retirada de itens. Revista Produto \& Produção, v. 7, n. 2, p. 27-38, 2004.

SUBRAMANIAM, V.; LEE, G. K.; RAMESH, T. et al. Machine selection rules in a dynamic job shop. International Journal of Advanced Manufacturing Technology, v. 16, p. 902-908, 2000.

cross ${ }^{\text {ref }}$

Nome completo: Shih Yung Chin / Eduardo Vila Gonçalves Filho

Filiação institucional: Escola de Engenharia de São Carlos

Departamento: Depto. de Engenharia Mecânica

Função ou cargo ocupado: Doutorando / Professor

Endereço completo para correspondência (bairro, cidade, estado, país e CEP): Av .Trabalhador São

Carlense, 400, Centro, São Carlos, SP, Brasil, CEP: 13560-970.

Telefones para contato: (16) 3373-9432

e-mail:sychin@sc.usp.br/evila@sc.usp.br 